\title{
A Novel Prototype Offset Multi Tubular Photoreactor (OMTP) for Solar Photocatalytic Degradation of Water Contaminants
}

\author{
Karen Sofía Ochoa-Gutiérrez ${ }^{1}$, Erick Tabares-Aguilar ${ }^{1}$, Miguel Ángel Mueses ${ }^{1}$, Fiderman Machuca- \\ Martínez $z^{2 *}$ and Gianluca Li Puma ${ }^{3}$ \\ ${ }^{1}$ Photocatalysis \& Solar Photoreactors Engineering, Chemical Engineering Program, Universidad de \\ Cartagena A.A. 1382 - Postal 195, Cartagena-Colombia \\ ${ }^{2}$ GAOX Research Group, School of Chemical Engineering, Universidad del Valle, A. A. 25360, Cali- \\ Colombia \\ ${ }^{3}$ Environmental Nanocatalysis \& Photoreaction Engineering, Department of Chemical Engineering, \\ Loughborough University, LE11 3TU, Loughborough, United Kingdom
}

E-Mails: Karenog18@gmail.com (Karen Sofía Ochoa-Gutiérrez); tabares0207@gmail.com (Erik TabaresAguilar); mmueses@unicartagena.edu.co (Miguel Angel Mueses); G.Lipuma@lboro.ac.uk (Gianluca Li Puma)

*Corresponding Author: fiderman.machuca@correounivalle.edu.co

\section{Graphical Abstracts}

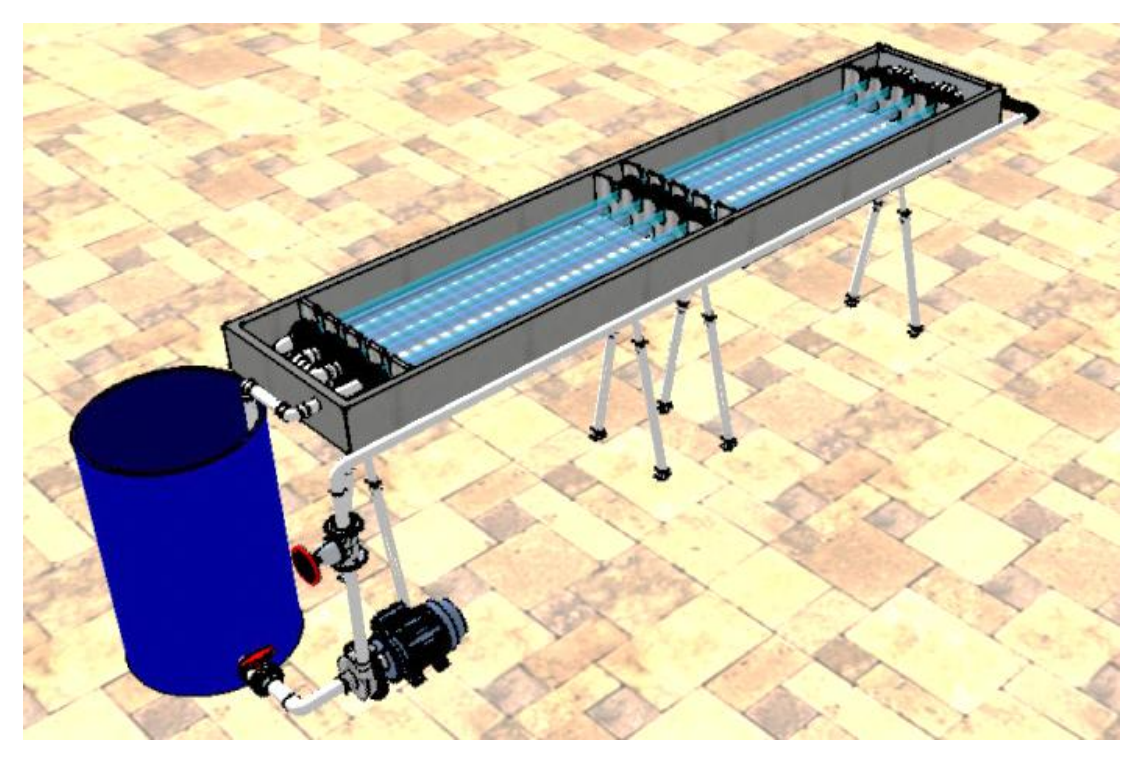

Graphical Abstract. OMTP solar photoreactor scheme (design using Sketchup®). 


\title{
A Novel Prototype Offset Multi Tubular Photoreactor (OMTP) for Solar Photocatalytic Degradation of Water Contaminants
}

\author{
Karen Sofía Ochoa-Gutiérrez ${ }^{1}$, Erick Tabares-Aguilar ${ }^{1}$, Miguel Ángel Mueses ${ }^{l}$, Fiderman Machuca- \\ Martínez $z^{2 *}$ and Gianluca Li Puma ${ }^{3}$ \\ ${ }^{1}$ Photocatalysis \& Solar Photoreactors Engineering, Chemical Engineering Program, Universidad de \\ Cartagena A.A. 1382 - Postal 195, Cartagena-Colombia \\ ${ }^{2}$ GAOX Research Group, School of Chemical Engineering, Universidad del Valle, A. A. 25360, Cali- \\ Colombia \\ ${ }^{3}$ Environmental Nanocatalysis \& Photoreaction Engineering, Department of Chemical Engineering, \\ Loughborough University, LE11 3TU, Loughborough, United Kingdom \\ *Corresponding Author: fiderman.machuca@correounivalle.edu.co
}

\section{Highlights}

- A Novel Prototype Offset Multi Tubular Photoreactor (OMTP) was developed.

- $\quad$ The OMTP is a simple modification of the compound parabolic collector (CPC).

- The reactor volume of the OMTP is up to $80 \%$ higher than the CPC for the same footprint.

- OMPT achieve significantly higher degradation efficiency of organic contaminant that CPC reactor.

- The OMTP should outperform the CPC in environmental and renewable energy applications. 


\title{
A Novel Prototype Offset Multi Tubular Photoreactor (OMTP) for Solar Photocatalytic Degradation of Water Contaminants
}

\author{
Karen Sofía Ochoa-Gutiérrez ${ }^{1}$, Erick Tabares-Aguilar ${ }^{1}$, Miguel Ángel Mueses ${ }^{1}$, Fiderman Machuca-Martínez ${ }^{2}$, and \\ Gianluca Li Puma ${ }^{3}$ \\ ${ }^{1}$ Photocatalysis \& Solar Photoreactors Engineering, Chemical Engineering Program, Universidad de Cartagena \\ A.A. 1382 - Postal 195, Cartagena-Colombia \\ ${ }^{2}$ GAOX Research Group, School of Chemical Engineering, Universidad del Valle, A. A. 25360, Cali-Colombia \\ ${ }^{3}$ Environmental Nanocatalysis \& Photoreaction Engineering, Department of Chemical Engineering, Loughborough \\ University, LE11 3TU, Loughborough, United Kingdom \\ Corresponding Author: fiderman.machuca@correounivalle.edu.co
}

E-Mails:

Karen Sofía Ochoa-Gutiérrez: Karenog18@gmail.com

Erik Tabares-Aguilar: tabares0207@gmail.com

Miguel Angel Mueses: mmueses@unicartagena.edu.co

Gianluca Li Puma: $\underline{\text { G.Lipuma@1boro.ac.uk }}$

*Corresponding Author: Fiderman Machuca-Martínez: fiderman.machuca@ correounivalle.edu.co 


\title{
A Novel Prototype Offset Multi Tubular Photoreactor (OMTP) for Solar Photocatalytic Degradation of Water Contaminants
}

\author{
Karen Sofía Ochoa-Gutiérrez ${ }^{1}$, Erick Tabares-Aguilar ${ }^{1}$, Miguel Ángel Mueses ${ }^{1}$, Fiderman Machuca-Martínez ${ }^{2}$, and \\ Gianluca Li Puma ${ }^{3}$ \\ ${ }^{1}$ Photocatalysis \& Solar Photoreactors Engineering, Chemical Engineering Program, Universidad de Cartagena \\ A.A. 1382 - Postal 195, Cartagena-Colombia \\ ${ }^{2}$ GAOX Research Group, School of Chemical Engineering, Universidad del Valle, A. A. 25360, Cali-Colombia \\ ${ }^{3}$ Environmental Nanocatalysis \& Photoreaction Engineering, Department of Chemical Engineering, Loughborough \\ University, LE11 3TU, Loughborough, United Kingdom \\ Corresponding Author: fiderman.machuca@ correounivalle.edu.co
}

\begin{abstract}
The design and operation of a new solar photoreactor prototype named Offset Multi Tubular Photoreactor (OMTP) is presented. The OMTP advances over the compound parabolic collector (CPC) photoreactor, which is one of the most efficient design for large-scale solar detoxification of water and wastewater. The OMTP design is based on a simple modification of the common CPC and included a supplementary set of tubes in the space occupied by the axes of intersection of the CPC reflective involutes. This new reactor configuration increased the irradiated reactor volume by $79 \%$ and the fluid residence time by up to 1.8 fold in comparison to the CPC, for the same solar irradiated area (footprint). The model parameters used for comparing and scaling the OMPT and CPC were $\beta$ (reactor volume/total volume), $\alpha$ (area of absorption/total volume), $\alpha_{g}$ (physical area/total volume), degradation efficiency $\eta_{\alpha}$ per unit area, and the operating volume. The total solar energy absorbed in the reactors $\left(1.74 \mathrm{~m}^{2}\right.$ footprint $)$ was $15.17 \mathrm{~W}$ for the CPC and 21.86 W for the OMTP, which represents an overall gain of $44 \%$ for the latter. The performance of the OMTP and CPC were compared at the same value of solar exposure $\beta$ of 0.3 with optimal photocatalyst loading of $0.25 \mathrm{~g} / \mathrm{L}$ titanium dioxide $\left(\mathrm{TiO}_{2} \mathrm{P} 25\right)$. The degradation efficiencies of methylene blue, dichloroacetic acid, 4-chlorophenol (120 ppm initial concentration) in the OMTP were up to $81 \%$, $125 \%, 118 \%$ and $242 \%$ higher, respectively, in comparison to the CPC after $8000 \mathrm{~J} / \mathrm{m}^{2}$ of accumulated solar energy. The OMTP should outperform the CPC in environmental and renewable energy applications of solar heterogeneous photocatalysis.
\end{abstract}

Keywords: Solar photocatalysis, OMTP and CPC photocatalytic reactor, $\mathrm{TiO}_{2}-\mathrm{P} 25$, Six Flux Model-HG 


\section{INTRODUCTION}

The efficient utilization of renewable solar energy is essential for the development of sustainable processes for the production of clean energy, biofuels, hydrogen, for environmental clean-up, water disinfection and for the exploitation of self-cleaning surfaces. Among these processes, solar photocatalysis has attracted industrial interest as a sustainable process for the mitigation of the environmental effects associated with water pollution [1]. Different applications of photocatalysis for the degradation and mineralization of water contaminants, such as pesticides, herbicides, dyes, emerging pollutants, phenols, and halogenated compounds, have been demonstrated at pilot-scale using solar radiation and commercial catalysts [2-5]. The most common pilot-scale solar photoreactors include parabolic trough reactors (PTRs), flat plate reactors (FPRs), Heliomans reactors (HLMR), double-skin sheet reactors (DSSRs), and compound parabolic collector (CPC) reactors [6]. Undoubtedly, the most widely used commercial solar reactor is the CPC, since it combines efficient capture of solar radiation (Figure 1) with favorable hydrodynamics resulting in effective water treatment.

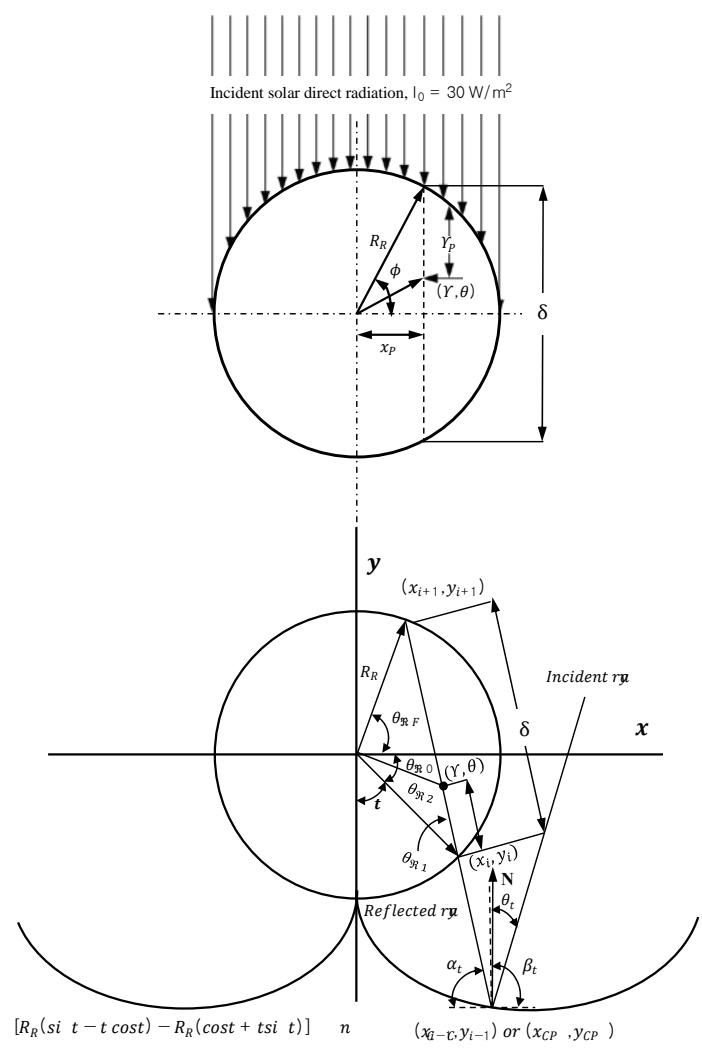

Figure 1. Geometric schematic of a CPC reactor with direct incident solar radiation of $30 \mathrm{~W} / \mathrm{m}^{2}$ (adapted from [7]) 
The CPC is essentially a tubular reactor with two highly polished, semi-involute, aluminium reflectors located at the bottom of the tube. This photoreactor is usually a static device inclined to the sun by an angle which maximize the absorption of solar light [1]. Its optical advantage lies in the redirection of both direct and diffuse solar light by the reflectors without excessive thermal effects on the water that flows inside the tube. The hydrodynamic advantage is presented by operation under turbulent flows with low power consumption costs, which ensure perfect lateral mixing and a homogeneous suspension of the catalyst particles. Furthermore, its closed configuration avoids the evaporation of volatile contaminants [2, 6, 8-15]. The materials used for its construction are in general inexpensive such as PVC for the fittings and Perspex for the tubes although the highly polished aluminium for the reflectors and the borosilicate glass as replacement for the Perspex tubes, have a relatively higher cost.

The design and optimization of the CPC photoreactor for water treatment has been performed using mathematical models that describe the incident solar radiation, the absorption and scattering of photons, the reaction kinetics, the hydrodynamics and the quantum efficiencies [8, 11, 16-25]. The models allow the selection of the optimal tube diameter and suspended catalyst concentration $[6,7,24]$, the evaluation of the type of semiconductor materials and the flow hydrodynamics [25]. Despite the favorable properties of the CPC photoreactor its design presents some fundamental limitations in commercial terms including low operating volumes of treatment in relation to the solar footprint occupied by CPC arrays and the apparent difficulty in scaling-up to large bore diameters due to the fragility of the pipe and the requirement for larger size end connections which increase costs and are prone to leaking.

In this study, the conceptual design and evaluation of a new prototype of an offset multi tubular solar photoreactor (OMTP), which mitigates the limitation of CPC and that can be adopted for industrial wastewater treatment is presented. The basic principle of this design is based on the removal of the costly CPC involute reflectors and in the introduction of a further set of tubes, which significantly increase the total reactor volume in relation to the solar footprint. The performance of the OMTP was evaluated and benchmarked against the CPC for the removal of methylene blue (MB), dichloroacetic acid (DCA), 4chlorophenol (4-CP), and phenol in water.

\section{DESIGN OF THE NEW SOLAR PHOTOREACTOR PROTOTYPE}

\subsection{Photoreactor design}

Figure 2 schematically shows the configuration of this new prototype, which is named the Offset Multi Tubular Photoreactor (OMTP). The design of the OMTP solar photoreactor prototype eliminates the use 
of costly parabolic involutes of conventional CPCs (Figure 2a) and introduces a further set of offset parallel tubes, with their axes located at the contact points of the CPC involutes, in the space occupied by the involutes. An optional polished aluminium flat reflector located at the bottom of the tubes could be fitted to improve the capture of solar light, although this is not an essential element.

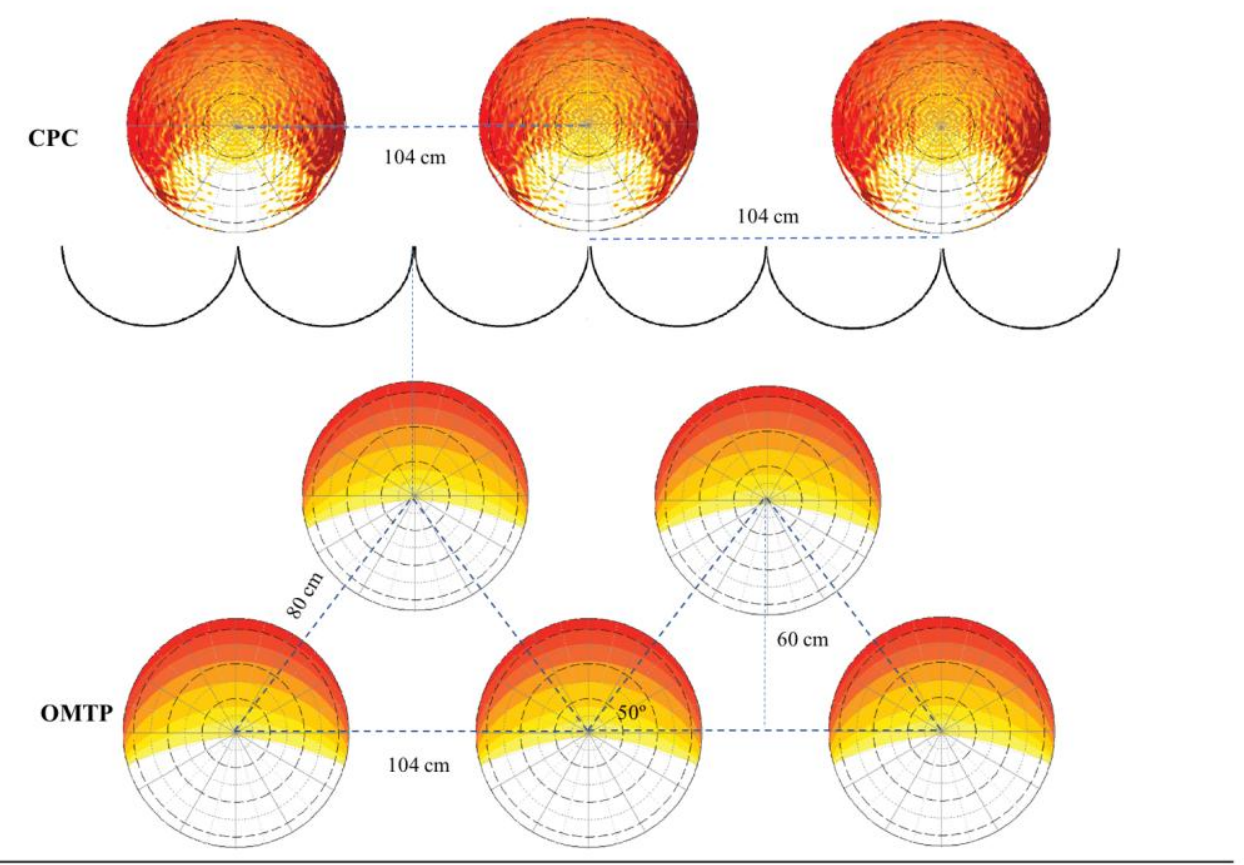

Figure 2. Distribution of tubes in a conventional CPC reactor (up) (adapted from [7]) and in an OMTP configuration (down)

The fundamental principle of this new design lies in the inclusion of $(2 n-1)$ set of reaction tubes, located over the vertices of isosceles triangle. The separations between tubes are showed in the Figure 2, which in comparison to a conventional CPC of $n$ tubes, significantly increase the total fluid residence time and operating volume of the reactor, while maintaining the same physical area (footprint) occupied by the solar collector (Figure 3). The further set of $(n-1)$ tubes in the OMTP is offset in comparison to the $n$ set of CPC, which also facilitate tubes connections. Table 1 compares the specifications of the OMTP photoreactor with those of a CPC, which were evaluated in this study. 
Table 1. Specifications of CPC reactor and OMTP.

\begin{tabular}{lll}
\hline Type of Reactor & CPC & OMTP \\
\hline Collector surface area* $\left(\mathrm{m}^{2}\right)$ & 1.74 & 1.74 \\
Collector length $(\mathrm{m})$ & 3.0 & 3.0 \\
Collector width $(\mathrm{m})$ & 0.58 & 0.58 \\
Collector height $(\mathrm{m})$ & 0.12 & 0.16 \\
Collector material & Zinc & Zinc \\
Tube material & Borosilicate & Borosilicate \\
Tube external diameter $(\mathrm{m})$ & 0.032 & 0.032 \\
Tube thickness (m) & 0.0014 & 0.0014 \\
Exposed tube length $(\mathrm{m})$ & 1.2 & 1.2 \\
Number of tubes & 10 & 18 \\
Absorption surface area** $\left(\mathrm{m}^{2}\right)$ & 1.2 & 1.1 \\
Exposed reactor volume $(\mathrm{L})$ & 8.04 & 14.46 \\
Involute material & Aluminum & ---- \\
Involute reflector angle & $90^{\circ}$ & ---- \\
Involute reflectivity & 0.85 & ----
\end{tabular}

* The collector area represents the space occupied by the reactor structural metal box **Represents the total area of the tubes exposed to sunlight 


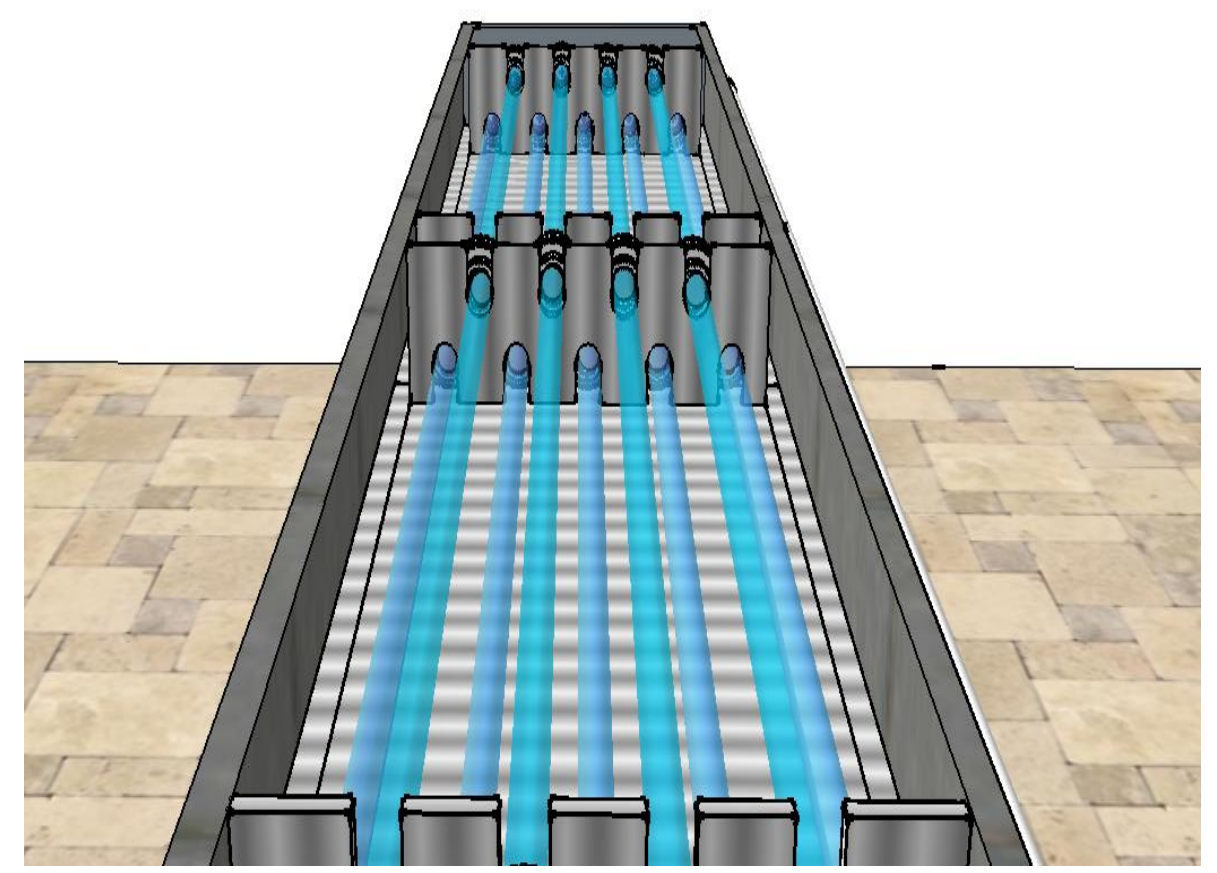

Figure 3. Proposed schematic design for the OMTP (design simulation using Sketchup®)

\subsection{Photoreactor performance parameters}

The design of an efficient photocatalytic reactor begins with its reactor geometry since this implicitly influences the photons paths, the optical thickness, and the optical limiting layer of the reactor [26]. In addition, the performance of a solar photoreactor is affected by the intensity of the incident radiation (direct and diffuse solar radiation), which is a function of the geographical latitude, session of year, hour of the day and the atmospheric conditions.

For an adequate comparison of the performance of solar photoreactors under variable solar conditions, the following scaling parameters have been considered:

$$
\begin{aligned}
& =\frac{S_{T}}{V_{R}} \\
& g=\frac{A_{T, \text { Collector }}}{V_{T}} \\
& =\frac{V_{R}}{V_{T}}
\end{aligned}
$$


$t_{W S}=\frac{1}{I_{G, U V}^{0}} I_{G, U V}(t)$

$\eta_{\alpha}=\frac{1}{\alpha}\left|\frac{C_{T O C}\left(t_{W S, 0}\right)-C_{T O C}\left(t_{W S, f}\right)}{C_{T O C}\left(t_{W S, 0}\right)}\right|$

$V_{T}=V_{R}+V_{D Z}$

where $\alpha$ is the ratio of the surface area $\left(S_{T}\right)$ to the volume $\left(V_{R}\right)$ of the transparent reactor tubes exposed to solar light; $\alpha_{g}$ is the ratio of the total area occupied by the collector structure $\left(A_{T, \text { Collector }}\right)$ and the total operating liquid volume $\left(V_{T}\right) ; \beta$ is the ratio of reactor volume to total liquid volume; $t_{W S}$ is the standard treatment time, $I_{G, U V}^{0}$ is the standard global average irradiance [3]; $I_{G, U V}(t)$ is the incident UV radiation at time $t ; \eta_{\alpha}$ is the degradation efficiency per unit area per unit treatment volume; $C_{T O C}\left(t_{W S, 0}\right)$ is the initial TOC concentration of the contaminant in the water at the initial time; $C_{T O C}\left(t_{W S, f}\right)$ is the final TOC concentration of the contaminant after a total time in which solar energy has been accumulated; and $V_{D Z}$ is the volume of the dark zone of the reactor usually also comprising a recycling system. The standard treatment time considers the variations in solar irradiance due to atmospheric changes.

\section{METHODOLOGY}

The common water contaminants phenol, dichloroacetic acid (DCA), 4-chlorophneol (4-CP) (all 99.9\% analytical grade from Merck $®$ ), and commercial-grade Methylene Blue (MB) typically used for kinetic studies in large-scale photocatalytic reactors [2] were used to evaluate the performance of the OMTP with respect to the CPC. Evonik-Degussa $\mathrm{TiO}_{2}-\mathrm{P} 25$ was used as the suspended catalyst, and commercial $\mathrm{HCl}$ $(0.2 \mathrm{M})$ was used to change the $\mathrm{pH}$ of the water. The overall concentration of the water contaminants was monitored with a total organic carbon (TOC-V CPH Shimadzu) and a UV-vis spectrophotometer (Labomed Spectro UV-2650). The instantaneous and accumulated solar radiation (Figure S1, Supporting Information) was monitored with a Delta Ohm 210.2 radiometer with an LP-UVB probe (300-360 nm) and the $\mathrm{pH}$ was measured with a Consort $\mathrm{pH}-$ meter $\mathrm{C} 931$.

The hydrodynamic performance was adjusted using the $\beta$ parameter (Eq. 3) with the volumetric flow in turbulent regime (Reynolds number $>20,000$ ) to avoid sedimentation of the catalyst. One inch PVC fittings were used to connect the borosilicate tubes. The water was circulated with a IWAKI-VMD40RLXT magnetic pump with a nominal power of $0.5 \mathrm{HP}$ and $35 \mathrm{~L} / \mathrm{min}$ maximum flowrate. 


\subsection{Experimental Evaluation of the OMTP Using Methylene Blue}

The removal of MB (10 ppm) by adsorption was evaluated with four catalyst concentrations $(0.20,0.25$, 0.30 , and $0.35 \mathrm{~g} / \mathrm{L})$ at natural $\mathrm{pH}(7.45 \pm 0.18)$. The tests were done using $100 \mathrm{ml}$ samples, which were continuously agitated in the dark for 4 hours in conical flasks. Aliquots were collected from these every 15 minutes to measure the residual concentration of MB by UV-Vis spectrophotometry.

The photocatalytic degradation of MB in the OMTP, at an initial concentration of $10 \mathrm{ppm}$ was evaluated at the catalyst concentrations $(0.00,0.20,0.25,0.30,0.35 \mathrm{~g} / \mathrm{L})$, at a volumetric flow rate of $24 \mathrm{~L} / \mathrm{min}$ and using a $\beta$ factor of $0.3\left(\mathrm{~V}_{\mathrm{R}}=9.7 \mathrm{~L}\right.$, see Table 1$)$. The range of catalyst concentrations investigated was established considering the optimization of tubular solar photoreactors which determined that for 32-mm diameter borosilicate glass tubes, the optimal operating concentration of $\mathrm{TiO}_{2}-\mathrm{P} 25$ should be between 0.20 and $0.40 \mathrm{~g} / \mathrm{L}[16]$.

The reactor set-up comprised the OMTP and the water recycle system, which included a stirred tank, where the solutions were made and samples were collected, a centrifugal pump and two control valves to control the recirculation flowrate.

In a typical experiment, the stirred tank was initially loaded with $29 \mathrm{~L}$ of tap water and the photocatalyst was added to form a slurry suspension and circulated in the reactor system for $10 \mathrm{~min}$. Then, $1 \mathrm{~L}$ of contaminant aqueous solution, at the required concentration, was added in the reactor system and the suspension was recirculated under darkness for $30 \mathrm{~min}$ to establish adsorption/desorption equilibrium conditions. Then a sample was taken and the reactor was exposed to solar light at $\left(\mathrm{t}_{\mathrm{sw}}=0\right)$. In situ measurements of dissolved oxygen, $\mathrm{pH}$ and temperature were monitored during the experiments (Table S1, Supporting Information). The reactor was exposed to solar light until a cumulative UV-B total energy of $8000 \mathrm{~J} / \mathrm{m}^{2}$ was reached. Samples were collected every 1000 units of accumulated energy, they were filtered, centrifuged, and analyzed by UV-Vis spectrophotometry. The same procedure was followed to monitor the contaminants degradation in the CPC reactor under solar light.

\subsection{Comparison of OMTP and CPC in the Degradation of Organic Pollutants}

The results of the degradation of phenol, DCA, and 4-CP were used to compare the performance of the OMTP and CPC photoreactors on a solar pilot scale with suspended $\mathrm{TiO}_{2}-\mathrm{P} 25$, at catalyst concentrations of $0.10 \mathrm{~g} / \mathrm{L}$ for phenol, $0.35 \mathrm{~g} / \mathrm{L}$ for DCA, and $0.5 \mathrm{~g} / \mathrm{L}$ for $4-\mathrm{CP}$. These values of catalyst concentrations were optimized in previous investigations carried out in a CPC reactor operated under identical 
experiment conditions and total incident solar radiation [16]. The initial $\mathrm{pH}$ of the water was 3.0 for phenol, 3.2 for DCA, and 3.5 for 4-CP, as recommended by [27]. The initial concentration of each contaminant in the water was 120 and $60 \mathrm{ppm}[26]$.

The $\beta$ factor in the CPC and OMPT reactor systems was held constant at 0.3 , and the volumetric flow rate in both systems was set at $24 \mathrm{~L} / \mathrm{min}$ to ensure a turbulent flow regime $(\operatorname{Re}=21140$ ) and uniform suspensions of the catalyst. In such way, the number of passes of the water through the reactors were the same, allowing a direct comparison of the two reactor systems. The physical area of the collector was

constant (one reactor module, $A_{T, \text { Collector }}=1.74 \mathrm{~m}^{2}$ ), while the total operating volumes were $36 \mathrm{~L}$ for the $\mathrm{CPC}$ and $65 \mathrm{~L}$ for the OMTP, respectively.

Continuous air bubbling in the recirculation stirred tank was provided to maintain the water under oxygen saturation conditions during the oxidation reaction which was carried out at the operating temperature of $33^{\circ} \mathrm{C} \pm 0.3$. The effect of molecular adsorption or direct photolysis of the contaminants tested were negligible and did not directly affect the photocatalytic process as previously shown [16].

The operating procedure for the solar heterogeneous photocatalysis tests were as described for the MB with sample collected every 1600 units of accumulated energy up to $8000 \mathrm{~J} / \mathrm{m}^{2}$. The samples after filtration and centrifugation were analyzed by TOC.

\subsection{Mathematical Evaluation of OMTP and CPC Performance}

The formulations of the modeling equations of the OMTP and CPC reactors are based on the generalized methodology (Fig. 4) for heterogeneous pilot-scale solar reactors, $\mathrm{TiO}_{2}-\mathrm{P} 25$ and natural solar radiation proposed by [16]. 


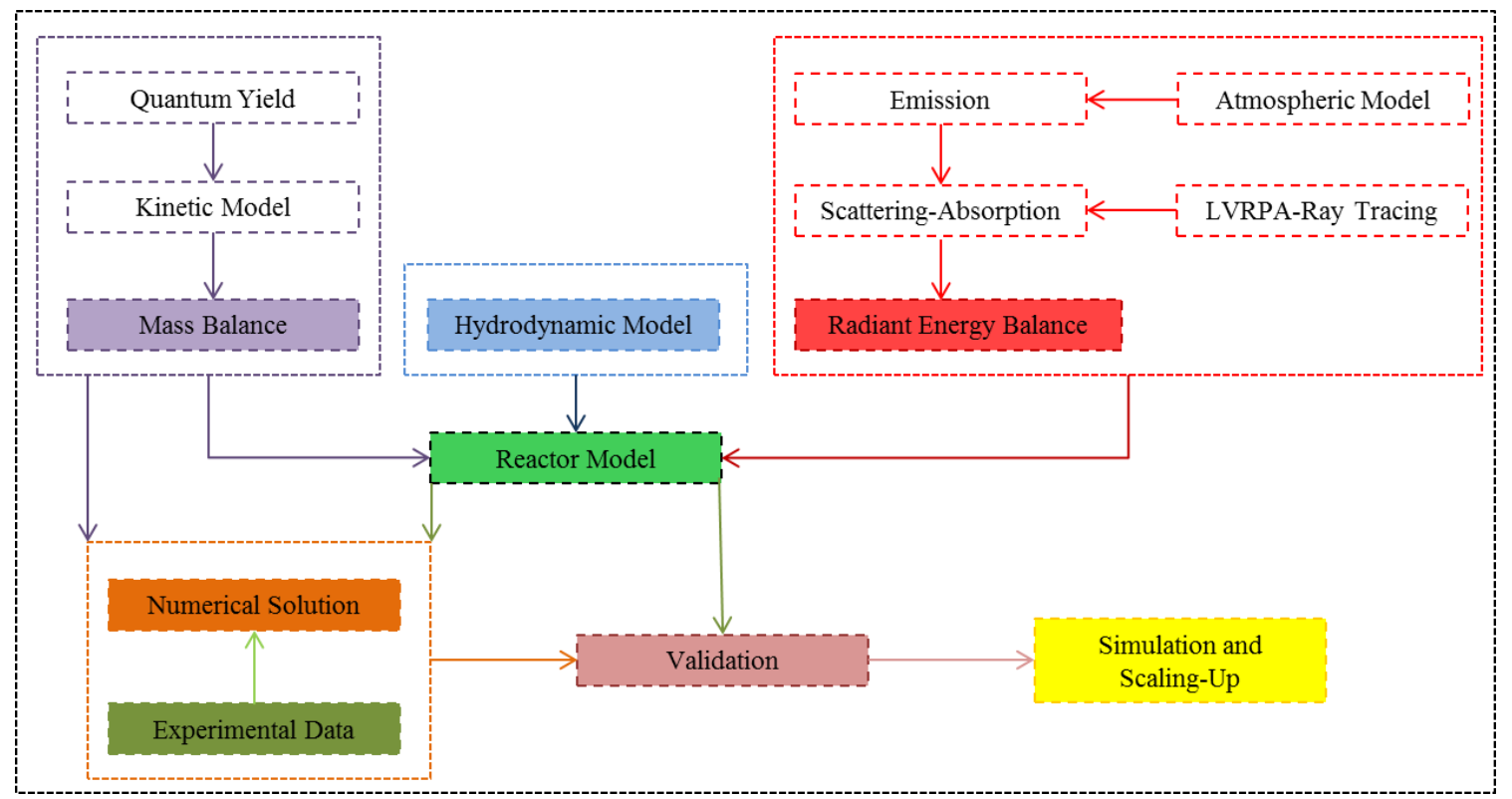

Figure 4. Methodological structure of the model. Adapted from [16].

Both OMTP and CPC reactors were modeled as flow-through reactors with total recycling, thus, the material balance could be described as an integral-differential equation as a function of the cumulative incident solar energy $\xi_{A E}$, the average total concentration of the contaminant, and the generalized kinetic model for the heterogeneous photocatalytic degradation of organic contaminants in the presence of $\mathrm{TiO}_{2}$ P25, under the concept of constant isotropic global parameters throughout the reactor volume $\left(\Phi_{g}\right.$ is quantum yield (mol/Einstein); $\hat{E}_{g\left(\lambda \rightarrow \lambda_{\prime}\right)}^{a}$ is Effective Volumetric Rate of Energy Absorption, VREA $\left(\right.$ Einstein $\left./ \mathrm{s} . \mathrm{m}^{3}\right) ; \alpha_{1}$ is the kinetic reaction rate constant $\left(\mathrm{mol} / \mathrm{m}^{2} \cdot \mathrm{s}\right) ; \kappa_{P}$ is the constant of particle $\left(\mathrm{m}^{3} / \mathrm{m}^{2}\right)$ and $k_{A}^{L-H}$ is absorption constant of the L-H model $\left.\left(\mathrm{m}^{3} / \mathrm{mol}\right)\right)$ [16]:

$$
\begin{aligned}
& \frac{d C_{i}}{d \xi_{A E}}=\frac{1}{\xi_{t}}\left(\frac{1}{V_{T}}\right) \int_{V_{R}}\left(-r_{i}\right) d v=-2 \beta \frac{\alpha_{1}}{\kappa_{P}}\left[-1+\sqrt{1+\frac{\kappa_{P}}{\alpha_{1}} \Phi_{g} \hat{E}_{g\left(\lambda \rightarrow \lambda^{\prime}\right)}^{a}}\right] \frac{k_{A}^{L-H} c_{i}}{1+k_{A}^{L-H} c_{i}} \\
& \xi_{t}=\frac{1}{\left(d \xi_{A E} / d t_{S W}\right)}
\end{aligned}
$$

where $\xi_{A E}$ is the slope of the experimental data relationship of the cumulative incident solar radiation vs. time for each experimental test, and $\xi_{t}$ is the inverse slope of the relationship of the incident radiation and standard treatment time. The $\xi_{t}$ function is proposed to account for the fluctuation of the incident solar irradiance due to atmospheric phenomena and time of the day. The model parameters in equation (7) have been reported in [16]. 
The incident solar radiation $I_{0}$ arriving on the reactors was modeled using the methodology reported by [15], which considers constant solar radiation in the longitudinal axis of the tubular reactors, corrected for the geographic position and time of the year of Cartagena-Colombia $\left(10^{\circ} 25^{\prime} 25^{\prime \prime} \mathrm{N}\right.$. L $\left.-75^{\circ} 31^{\prime} 31^{\prime \prime} \mathrm{W}\right)$. At this latitude the upper tubes did not produced shadows to the lower tubes during the experimental time. The local volumetric rate of photon absorption (LVRPA), which describes the effect of photon absorption and scattering in the reactor, was quantified using the SFM-HG model [24]:

$$
\frac{L V R P A}{I_{0}}=\frac{1}{\lambda_{\omega_{\text {corr }}} \omega_{\text {corr }}(1-\gamma)}\left[\omega_{\text {corr }}-1+\sqrt{1-\omega_{\text {corr }}{ }^{2}} e^{\frac{-x}{\lambda_{\omega_{\text {corr }}}}}+\gamma\left(\omega_{\text {corr }}-1-\sqrt{1-\omega_{\text {corr }}{ }^{2}} e^{\frac{x}{\lambda_{\omega_{\text {corr }}}}}\right)\right]
$$

The values of the absorption $(\kappa)$ and scattering $(\sigma)$ coefficients were as those in [28] and the probabilities of forward, backward and side scattering for $\mathrm{TiO}_{2}-\mathrm{P} 25$ were $p_{f}=0.754, p_{b}=0.133$ and $p_{s}=0.027$ [24].

The model parameters depend on the ray pathlenghs $\delta$ (Figure 1), which for tubular and CPC reactors were evaluated using the methodology of [7] and [15].

Finally, the hydrodynamic performance of the reactor was that of perfectly mixed batch reactor due to the large circulation ratio and small conversion per pass. The mass balance of the batch reactor (Eq. 7) is an equation in grouped parameters, independent of the geometrical coordinates. Therefore, the properties of the reaction suspension (fluid + suspended particles) were assumed as a pseudo-homogeneous mixture. The parameters in the mass balance were modeled as constant isotropic global parameters and in consequence a hydrodynamic model became redundant.

\section{RESULTS AND DISCUSSION}

\subsection{Evaluation of the optical and hydrodynamic performance of the reactor}

The optical comparison of the OMTP with respect to the CPC was quantified using the overall volumetric rate of photon absorption (OVRPA) [16] (Eq. 10).

$O V R P A=\frac{1}{V_{R}} \int_{V_{R}} L V R P A(V) d V$ 
The reactor to total volume ratio $\beta$, is a scaling parameter that is indirectly related to the performance of the pumping system. In order to maintain optimal pump operation (suction and discharge), turbulent flow conditions and uniform suspension of the catalyst [12], the minimum $\beta$ ratio was 0.27 . The reactor systems were therefore operated with an overshoot factor of $10 \%(\beta=0.3)$ and with total volumes of $32 \mathrm{~L}$ for the CPC and $58 \mathrm{~L}$ for the OMTP.

Figure 5 shows the LVRPA distribution on a cross section of the CPC and OMPT calculated using the SFM-HG model and $0.25 \mathrm{~g} / \mathrm{L} \mathrm{TiO}_{2}-\mathrm{P} 25$, on a clear sunny day. The equivalent values of the OVRPA were $1887.94 \mathrm{~W} / \mathrm{m}^{3}$ for the CPC and $1511.07 \mathrm{~W} / \mathrm{m}^{3}$ for the OMTP, and the total solar power absorbed in the CPC and OMPT collectors were $15.17 \mathrm{~W}$ for the CPC $\left(1887.94 \mathrm{~W} / \mathrm{m}^{3} \times 0.00804 \mathrm{~m}^{3}\right)$ and $21.86 \mathrm{~W}$ for the OMTP $\left(1511.07 \mathrm{~W} / \mathrm{m}^{3} \times 0.01446 \mathrm{~m}^{3}\right)$, representing an optical gain of $44 \%$ for the latter. The OMTP advantage is reflected in increased system degradation efficiencies and larger operation volumes $\left(V_{T}\right)$. These values are consistent with previous reports [24].
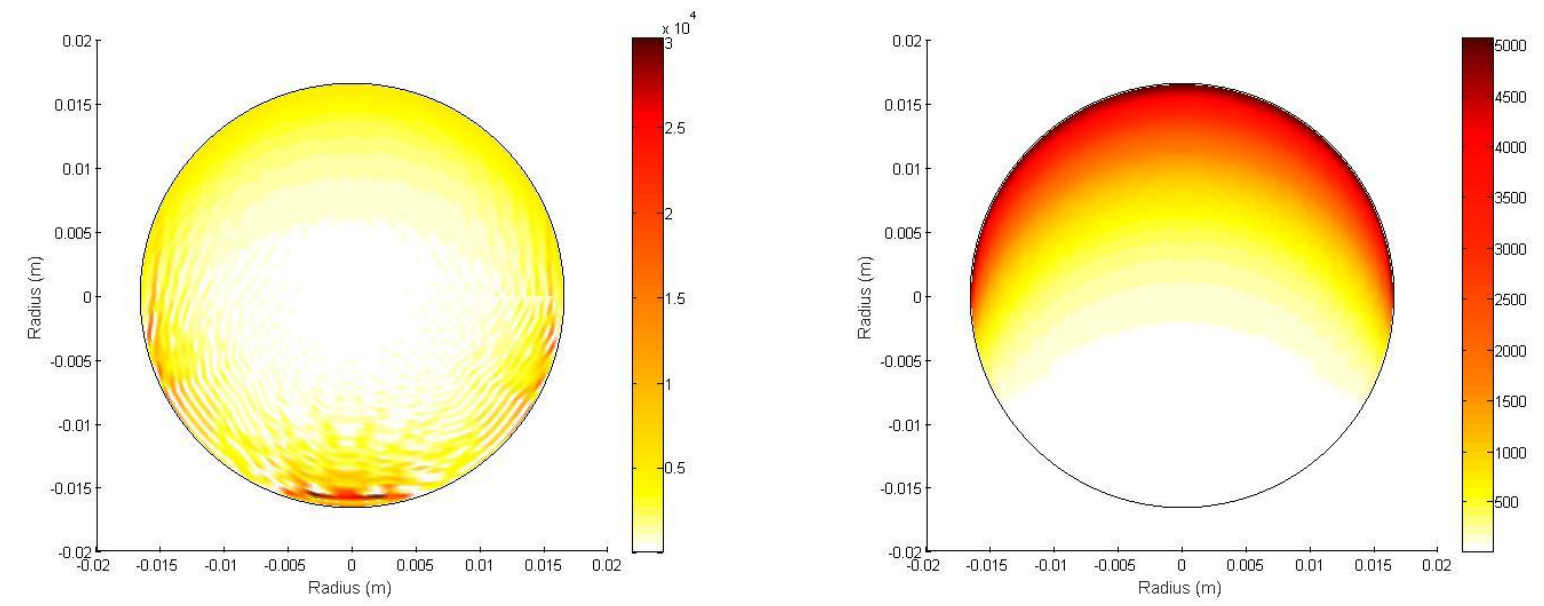

a

Figure 5. Distribution of LVRPA using SFM-HG: a) CPC reactor and b) OMTP for a $\mathrm{TiO}_{2}-\mathrm{P} 25$ catalyst loading of $0.25 \mathrm{~g} / \mathrm{L}$.

\subsection{OMTP and CPC footprints and process economics}

The primary limitations of the CPC reactor are the treatment volume capacity and the area occupied by each collector module, particularly considering that large exposure areas are required to ensure the treatment of industrially relevant operating volumes [1]. A second advantage in the operation of largescale reactors with the new prototype compared with the CPC is that the ratio of the physical area occupied by the collector to the total volume of treatment $\left(\alpha_{g}\right)$ could be lower, which would demonstrate 
its viability in the scaling of photocatalysis processes for industrial wastewater applications on a commercial scale. This means that for smaller $\alpha_{g}$ factors, fewer solar reactors and smaller footprint would be required for a given volume of treatment, which would thereby improve the costs of initial investment, maintenance, and operating costs. Table 2 shows the $\alpha_{g}$ ratios for the pilot-scale CPC reactors reported in the literature.

From the point of view of irradiated volume, four OMTPs are equivalent to seven CPCs but with higher photon efficiencies than that of the latter, as discussed below. The hydraulic optimization of the system shows that the energy consumption per liter of treated wastewater would be lower in the designed OMTP and that to maintain the turbulent flow with a flow rate higher than $24 \mathrm{~g} / \mathrm{L}$, a 0.30 -HP magnetic pump is theoretically required as opposed to a 0.24 -HP pump for a CPC. The difference in the energy cost is compensated in treating higher volumes with efficiency increases.

Table 2. Ratio of the physical area of the collector per treatment volume for solar CPC reactors and OMPT.

\begin{tabular}{llll}
\hline Reference & $\boldsymbol{A}_{T, \text { Collector }}\left(\mathrm{m}^{2}\right)$ & $\boldsymbol{V}_{T}\left(\mathrm{~m}^{3}\right)$ & $\alpha_{g}\left(\mathrm{~m}^{2} / \mathrm{m}^{3}\right)$ \\
\hline OMTP & 1.74 & 0.058 & 29 \\
CPC & 1.74 & 0.032 & 53 \\
{$[29]$} & 4.5 & 0.060 & 80 \\
{$[30]$} & 1.37 & 0.025 & 60 \\
{$[31]$} & 2.12 & 0.050 & 40 \\
{$[32]$} & 3.08 & 0.035 & 90 \\
\hline
\end{tabular}

Moreover, the initial investment costs for the construction of an OMTP module, although slightly higher than that of the CPC, are compensated for by its implementation with smaller numbers of arrays of CPC modules in series with the same arrangement and distribution. If the arrangements of the same type are considered, the cost of the construction area will be 1.8 times lower than that of the CPC. Table 3 presents the costs in US dollars at the current exchange rate for the construction of a reactor module.

Table 3. USD costs for construction of a CPC reactor and an OMTP in Colombia (Reference year 2014).

\begin{tabular}{lll}
\hline Concept & CPC & OMTP \\
\hline Borosilicate tubes & 130 & 235 \\
Collector and supports & 550 & 550 \\
\hline
\end{tabular}




\begin{tabular}{lll}
\hline Reflectors (involutes) & 100 & --- \\
Recycling tanks & 15 & 15 \\
Magnetic pump & 100 & 100 \\
PVC tubing and accessories & 85 & 120 \\
Seals, resins, adhesives, and Teflon & 80 & 90 \\
Labor & 200 & 250 \\
\hline Total & 1260 & 1360 \\
\hline Operation/day* & 13 & 14 \\
\hline$*$ Energy, catalyst and maintenance & based on 12 hours of operation, power of pump and volume of \\
treatment. &
\end{tabular}

\subsection{Evaluation of heterogeneous photocatalytic degradation of organic compounds}

\subsubsection{Degradation of methylene blue}

The performance of the heterogeneous photocatalytic degradation of methylene blue with suspended $\mathrm{TiO}_{2}-\mathrm{P} 25$ using natural solar radiation in the OMTP is shown in Figure 6. This is reported as the percentage of degradation \% Deg as a function of the accumulated UV-B energy:

$\% \operatorname{Deg}=\left(\frac{C_{M B}(\xi=0)-C_{M B}\left(\xi\left(t_{W S}\right)\right)}{C_{M B}(\xi=0)}\right) \times 100$

The reaction rates of methylene blue were the highest for accumulated energies of less than 2000 units, under optimal catalyst loading $(0.25 \mathrm{~g} / \mathrm{L})$. The rate increased at lower catalyst loadings and then decreased at higher catalyst loadings $(>0.25 \mathrm{~g} / \mathrm{L})$ as a result of the increase of the photon shielding effects. The photon scattering and shielding effects are a function of the optical thickness of the suspension, which in turn depend on the catalyst concentration, the optical properties of the catalyst suspension (absorption and scattering coefficients and scattering phase function) and the geometrical thickness of the suspension. The optical thickness at the higher catalyst concentration $(0.35 \mathrm{~g} / \mathrm{L})$ was 2.06 , while at the lower catalyst concentrations $(0.2 \mathrm{~g} / \mathrm{L})$ it was 1.18 . These results are consistent with previous simulation results reported in the literature [7]. 
However, for all four concentrations of $\mathrm{TiO}_{2}-\mathrm{P} 25$ used, degradation greater than $99 \%$ were reached for an accumulated energy of $8000 \mathrm{~J} / \mathrm{m}^{2}$ and for treatment times of less than 70 minutes. This is primarily due to the direct effects of increased residence time, illuminated reactor volume and overall absorbed solar energy, and the contribution of direct photolysis.

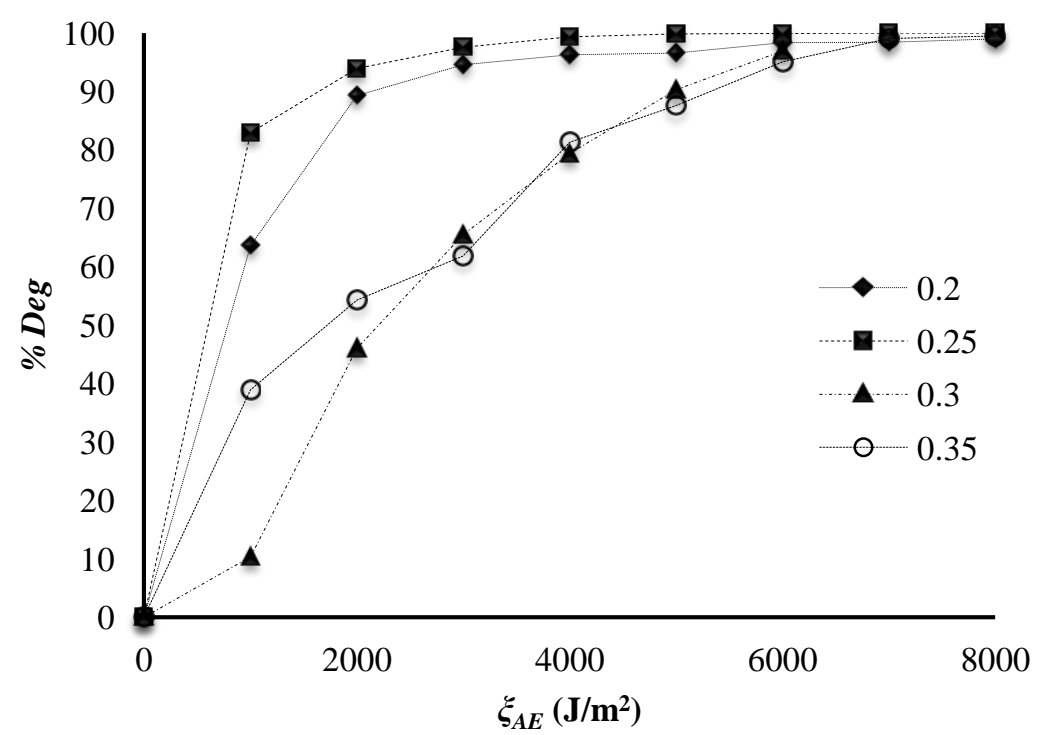

Figure 6. Performance of methylene blue degradation in a pilot-scale OMTP solar reactor at different $\mathrm{TiO}_{2}-\mathrm{P} 25$ catalyst concentrations $(0.2,0.25,0.3$, and $0.35 \mathrm{~g} / \mathrm{L})$.

The effect of direct photolysis of MB in the OMTP showed a degradation of $46 \%$ at an accumulated energy of $8000 \mathrm{~J} / \mathrm{m}^{2}$, which compares to only $10 \%$ in the CPC reactor operated under identical conditions (see Figure 7.a). This improvement in performance evidences the effect of favourable reactor geometry in the OMPT and the corresponding increase of the surface area and reactor volume exposed to the sun with respect to the CPC. Literature studies have reported degradation of methylene blue in the absence of a catalyst, obtaining values of less than $10 \%$ for CPC reactors and up to $20 \%$ in a small-scale rotary reactor using UV lamps [33-36]. Considering that this compound is highly recalcitrant and exhibits resistance to biodegradation, the effect of photolysis on the heterogeneous solar photocatalysis process may be beneficial and may decrease the contact time in large-scale treatment systems. In contrast, adsorption experiments under darkness in the pilot plant showed reductions in the initial loading of the contaminant of less than $2 \%$ during the homogenization time, therefore, these can be neglected on the effect of heterogeneous solar photocatalysis of MB.

\subsubsection{Degradation of phenol, DCA, and 4-CP}


Heterogeneous photocatalytic degradation of phenol, DCA, and 4-CP was performed in a heterogeneous photocatalytic solar platform at the University of Cartagena, Colombia $\left(10^{\circ} 25^{\prime} 25^{\prime \prime} \mathrm{N}-75^{\circ} 31^{\prime} 31^{\prime \prime} \mathrm{O}\right)$ on sunny and clear days at a specific hour to ensure that environmental atmospheric conditions did not significantly affect the process. The incident solar radiation measured during the experiment period (2016) and the slopes of the linear relationship with the accumulated UV-B radiation during the treatment time is presented in Supplementary Information (Figs. S1-S5). The observed conversion of TOC at 8000 $\mathrm{J} / \mathrm{m}^{2}$ of energy accumulated for these three compounds at different initial TOC concentrations in both the OMTP and CPC are presented in Table 4 by applying Eq. (11).

Table 4 Percentages of heterogeneous photocatalytic degradation for Phenol, DCA, and 4-CP in OMTP and CPC solar reactors for total accumulated energies of $8000 \mathrm{~J} / \mathrm{m}^{2}$.

\begin{tabular}{|c|c|c|c|c|c|c|}
\hline \multirow{3}{*}{$\begin{array}{l}\text { \%Deg } \\
\text { Reactor }\end{array}$} & \multicolumn{2}{|c|}{ Phenol } & \multicolumn{2}{|c|}{ DCA } & \multicolumn{2}{|c|}{ 4-CP } \\
\hline & $C_{T O C, 0}$ & $C_{T O C, 0}$ & $C_{T O C, 0}$ & $C_{T O C, 0}$ & $C_{T O C, 0}$ & $C_{T O C, 0}$ \\
\hline & 60 ppm & 120 ppm & 60 ppm & 120 ppm & 60 ppm & 120 ppm \\
\hline OMTP & 24.15 & 29.69 & 55.58 & 72.86 & 20.68 & 22.19 \\
\hline СРC & 20.31 & 19.36 & 53.41 & 68.26 & 28.17 & 21.42 \\
\hline$C_{\text {Cat }}$ & \multicolumn{2}{|c|}{$0.10 \mathrm{~g} / \mathrm{L}$} & \multicolumn{2}{|c|}{$0.35 \mathrm{~g} / \mathrm{L}$} & \multicolumn{2}{|c|}{$0.50 \mathrm{~g} / \mathrm{L}$} \\
\hline
\end{tabular}

The results show that for the established operating conditions, the percentages of TOC degradation favor the OMTP with respect to the CPC. The advantage of the OMTP over the CPC lies in the higher operating volume per footprint exposed to sunlight. The lower degree of phenol and 4-CP degradation in comparison to DCA, does not depend on the geometry of the reactor, but results from the highly recalcitrant intermediates that are generated during the mineralization process $[12,37,38]$. 4-CP primarily produces 4-chlorocatechol (4-CC), hydroquinone (HQ), 1,4-benzoquinone (BQ), acetylene, and maleic acid, during the treatment, however, these are consumed with the reagent by effect of the high attack of hydroxyl radicals due to high photonic performance of the reactor [23, 31, 38]. Phenol, instead generates p-benzoquinone (p-BQ), HQ, and catechol (CC), which, similarly to the 4-CP intermediates, suffer high molecular adsorption on the surface of $\mathrm{TiO}_{2}$ that competes with the multilayer adsorption of $\mathrm{H}_{2} \mathrm{O}$, thus reducing the probability of photogenerated electron capture, decreasing $\mathrm{OH}^{*}$ production, and increasing surface recombination $[39,40]$.

In contrast, the photocatalytic degradation of DCA proceeded at much higher rates compared to phenol and 4-CP, which results from the simultaneous attack by photogenerated holes $(\mathrm{h}+)$ and hydroxyl radicals 
on the dissociated dichloroacetate ions in aqueous phase [12,41]. The direct attack of dichloroacetate ions by the photogenerated holes form dichloroacetate radicals and then $\mathrm{CO}_{2}$ and dichloromethyl radicals by decarboxylation. These react with molecular oxygen adsorbed on the surface of the catalyst, forming dichloromethylperoxyl radicals. These two molecules together form $\mathrm{H}_{2} \mathrm{O}_{2}$ and phosgene. $\mathrm{H}_{2} \mathrm{O}_{2}$ enhances electron capture on the photocatalyst surface, which thereby benefits the formation of hydroxyl radicals, while phosgene is hydrolyzed to $\mathrm{HCl}$ and $\mathrm{CO}_{2}$ [41]. Simultaneously to the above mechanism, the hydroxyl radicals formed by the oxidation of water/protons at the surface of the photocatalyst may also attack DCA and the reaction intermediates $[12,17]$.

\subsubsection{Effect of geometry}

Although contaminants reaction mechanisms are intrinsic to the nature of the reagent and its interaction with the photocatalyst, the rate of generation of the oxidant species is a function of the rate of photon absorption in the reactor, which in turn depends on the reactor geometry. The degradation efficiency of $\mathrm{MB}$, phenol, DCA, and 4-CP, respectively, per unit area and per unit treatment volume, $\eta_{\alpha}$, as a function of the accumulated energy $\xi_{A E}$ in both OMTP and CPC is shown in Fig. 7. The OMTP displayed much higher efficiencies than in the CPC. After $8000 \mathrm{~J} / \mathrm{m}^{2}$ of accumulated solar energy, the $\eta_{\alpha}$ for MB degradation was $81 \%$ higher in the OMTP (Figure 7a). At higher initial concentrations (120 ppm) the $\eta_{\alpha}$ degradation for phenol was $242 \%$ higher (Figure $7 b$ ), 125\% higher for DCA (Figure 7c), and 118\% higher for 4-CP (Figure 7d) in the OMTP in comparison to the degradation efficiency in the CPC. At lower contaminant concentration (60 ppm), the $\eta_{\alpha}$ percentages were $151 \%$ (phenol), 150\% (DCA), and 55\% (4$\mathrm{CP}$ ) higher in the OMTP than in the CPC. In general, the results shown that at high initial concentration of contaminants the degradation performance always is much better in compare of low initial concentration, this is due to the reaction order which is higher than zero on evaluated systems and therefore a faster rate is expected at higher initial concentrations.

These results represent a fundamental contribution to the scaling processes of solar heterogeneous photocatalysis applications because higher efficiencies in the OMTP were obtained using the same physical installation area of collector $\left(1.74 \mathrm{~m}^{2}\right)$. In addition, the OMTP worked with a volume 1.8 times greater than the CPC volume. For multiple solar reactor panels these advantages will scale linearly. 


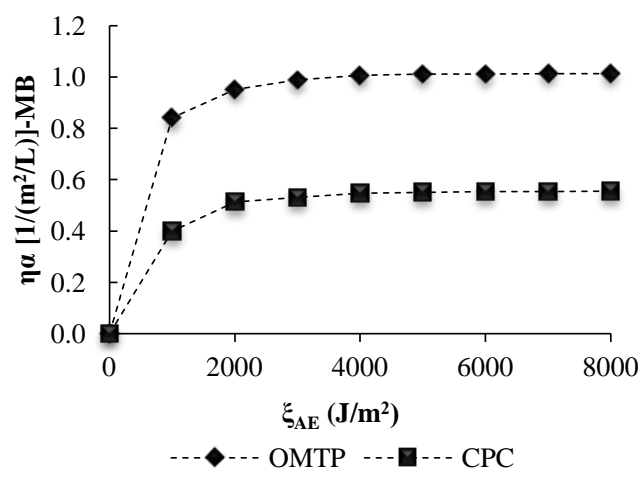

C

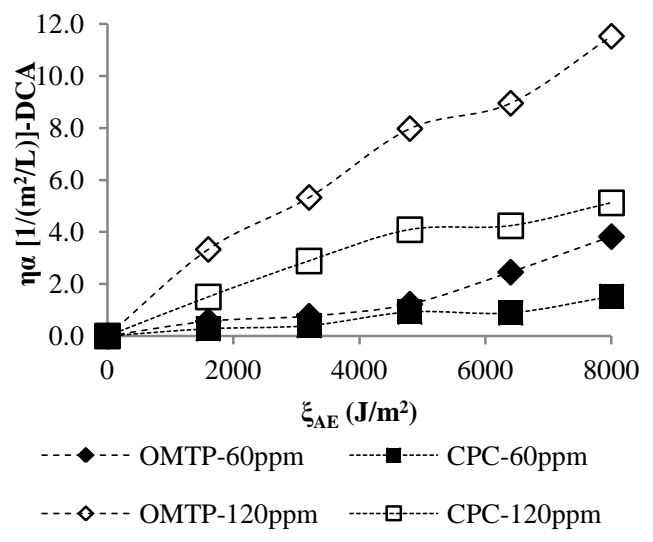

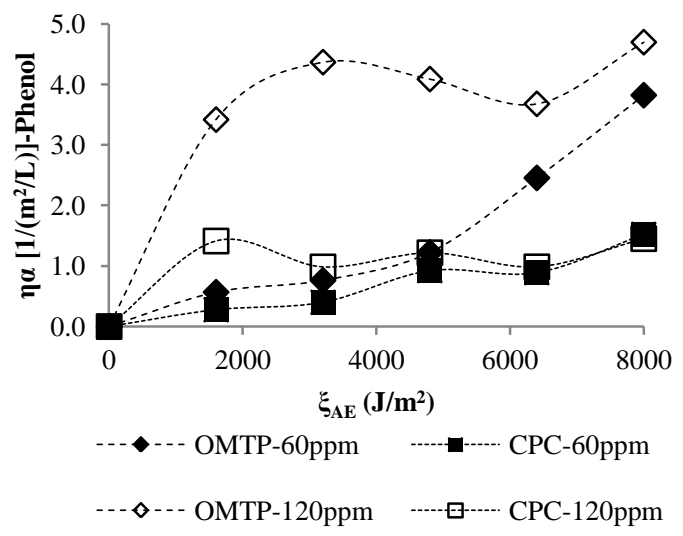

$\mathrm{b}$

d

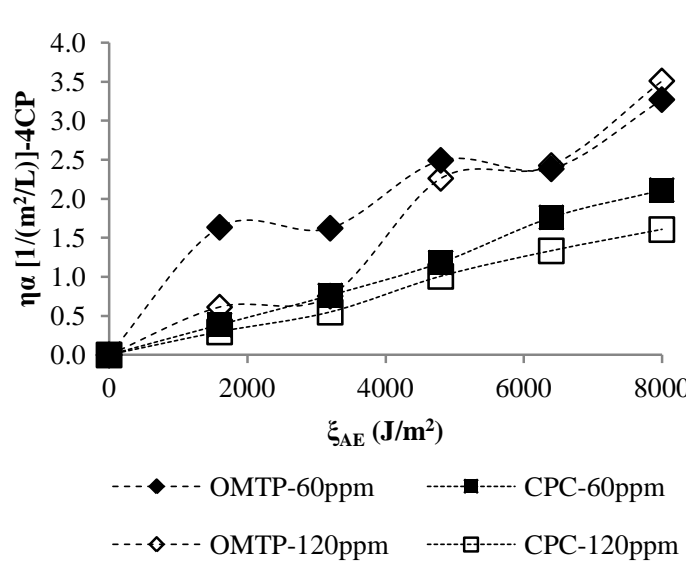

Figure 7. Efficiency of photocatalytic degradation at OMTP and CPC solar reactors per unit area and volume of operation: a) Methylene Blue b) Phenol, c) DCA and, d) 4-Chlorophenol.

\subsection{Mathematical evaluation of OMTP and CPC photoreactor performance}

Mathematical modeling of the photoreactor systems by combining the mass balances, the solution of the radiation balance (LVRPA), the reactor hydrodynamics and the reaction kinetics, permits to evaluate the concentrations of contaminants as a function of the accumulated energy. The model is also required for the design of solar water detoxification plants. The performance of the heterogeneous photocatalytic degradation processes in both OMTP and CPC was quantified by the solution of the photoreactor model (Eq. 7 coupled with Eq. 9) using the 4th-order Runge-Kutta method and the optimization algorithm of Nelder and Mead [42] for the determination of the kinetic parameters, which fits the model to the experimental results. The robustness of the mathematical model generated high predictions of the experimental data with average total error of less than $1.6 \%$ and with deviations close to zero (Figure 8). 

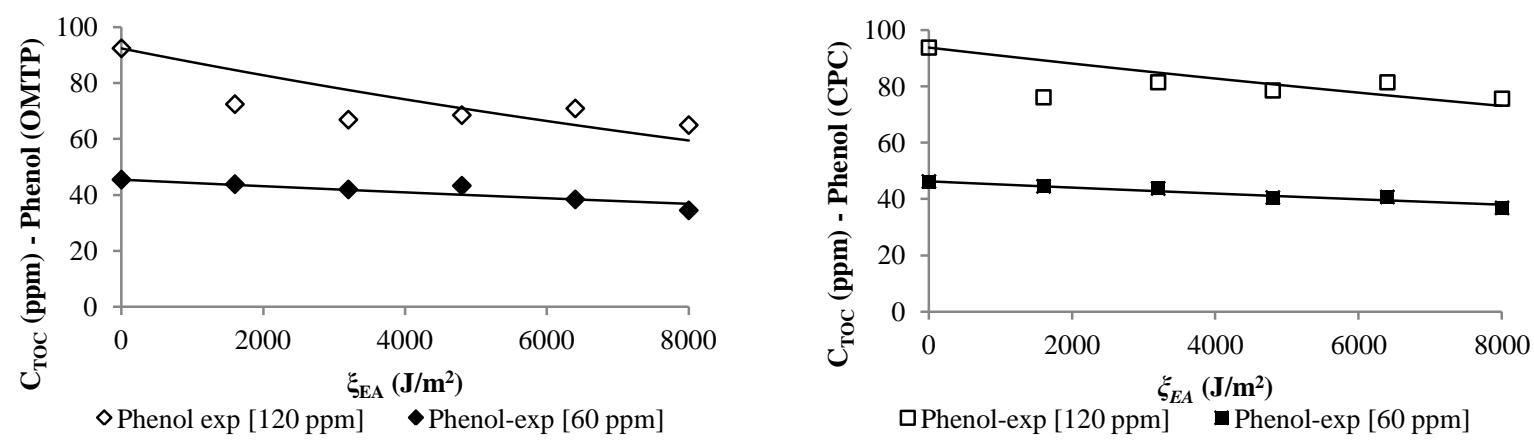

a
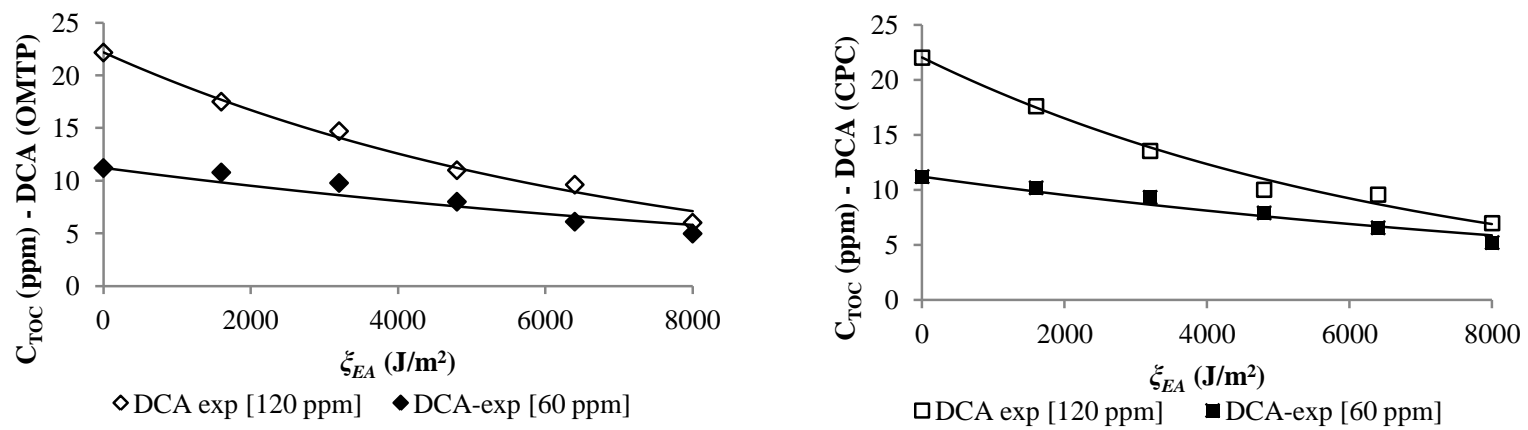

b
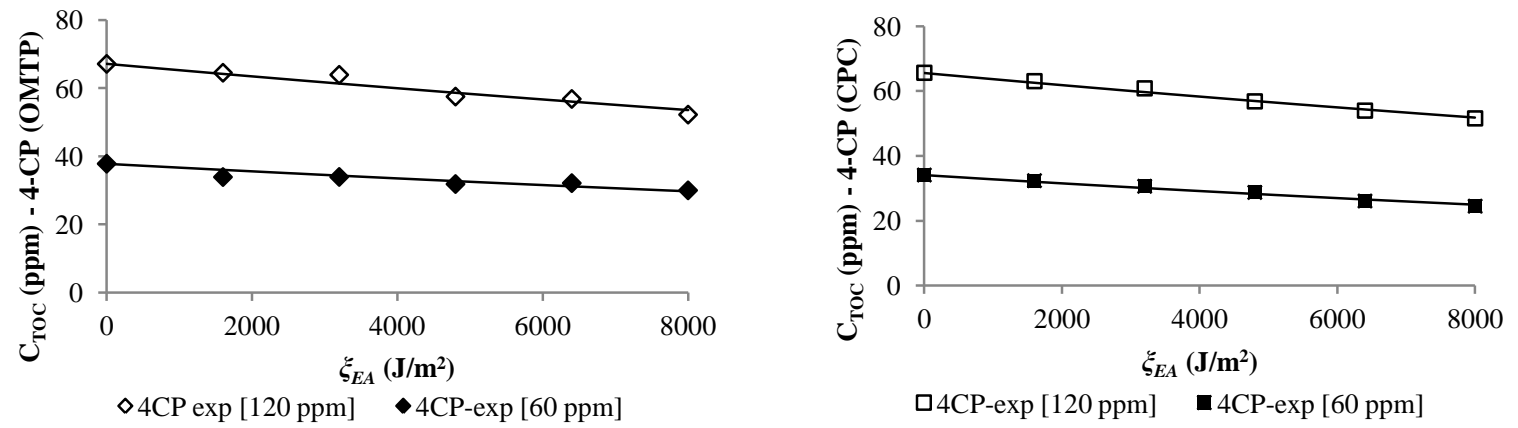

$\mathrm{c}$

Figure 8. Predictive capacity of the model for the description of heterogeneous solar photocatalytic degradation in the OMTP and CPC reactor for a) phenol, b) DCA, and c) 4-CP with suspended $\mathrm{TiO}_{2}-\mathrm{P} 25$ and natural solar radiation in Cartagena, Colombia

The determined kinetic parameters $\alpha_{1}, \kappa_{A}^{\text {L-Hand }}$ and $\eta$ are shown in Table 5. For the three compounds evaluated, the overall reaction rate efficiencies in the OMTP were 40\% (average) higher than in the CPC due to the higher rate of photon absorption and larger reactor volume. The longer mean residence time in 
the illuminated zone of the OMTP as a result of a greater number of tubes results in higher rates of contaminants mineralization incorporating the intermediates formed during the reactions (Figure 8) [1].

Table 5. Overall kinetic parameters of the model and $\eta^{*}$ parameter for photocatalytic degradation of phenol, DCA, and 4-CP.

\begin{tabular}{|c|c|c|c|c|c|c|c|}
\hline \multirow{3}{*}{ Compound } & \multirow{3}{*}{$\alpha_{1} \times 10^{4}$} & \multicolumn{2}{|l|}{ OMTP } & \multicolumn{3}{|c|}{ CPC } & \multirow{3}{*}{$\frac{\eta_{\text {OMTP }}-\eta_{C P C}}{\eta_{C P C}}$} \\
\hline & & $\kappa_{A}{ }^{L-H} \times 10^{4}$ & $\eta \times 10^{4}$ & $\alpha_{I} \times 10^{4}$ & $\kappa_{A}{ }^{L-H} \times 10^{4}$ & $\eta \times 10^{4}$ & \\
\hline & & & & & & & \\
\hline Phenol & 8.18 & 1.41 & 2.934 & 5.75 & 0.96 & 1.960 & 0.4969 \\
\hline DCA & 9.47 & 1.63 & 2.847 & 9.05 & 1.56 & 1.804 & 0.5782 \\
\hline 4-CP & 3.87 & 0.63 & 1.810 & 3.57 & 0.56 & 1.730 & 0.462 \\
\hline
\end{tabular}

$*_{\eta}$ is the degradation per unit of collector area and per treatment volume.

The kinetic performance is affected for the molecular absorption mechanisms. The generalized kinetic model used in this evaluation (Eq. 7) was based on Turchi and Ollis mechanism [8, 16, 17]. The absorptive processes in the solid-liquid interface are strongly competitive on molecular transportation of the reactive species and the kinetic of reaction rate [16]. The competition of molecular absorption of contaminant over $\mathrm{TiO}_{2}$ surface in the OMTP is also affected by the reactor geometry. The constants $\kappa_{A}{ }^{L-H}$ of the model also have higher values in the OMTP. This result is consistent due that the molecular absorption of the process is not an equilibrium process because it is a kinetic constant of adsorption. The dynamic of the competitive molecular absorption is affected by the longer residence time and the total volume of operation, whereby the effects of molecular transport of the substrates to the catalyst surface and their adsorption increase. Finally, these kinetic contributions favor photonic efficiencies $\eta(\mathrm{ppm} / \mathrm{J})$ [2], which are higher in the OMTP in comparison to the CPC reactor (Table 5), because of the higher reaction volume and total solar power absorbed in this reactor.

\section{CONCLUSIONS}

This study has presented a new solar reactor prototype (OMTP) which addresses some of the limitations of current CPC solar reactors used in industrial wastewater treatment. The OMTP increase the total treatment volume, the residence time, decrease the footprint, and simplify scale-up in comparison to the CPC. This new reactor includes an additional arrangement of tubes in the space occupied by the CPC involutes. The fluid residence time in the OMPT increased by up to 1.8 times. The net solar global energy absorbed in the OMPT increased by up to $44 \%$, which translated in MB, DCA, 4-CP and phenol 
degradation efficiencies up to $81 \%, 125 \%, 118 \%$ and $242 \%$ higher, respectively, in comparison to the CPC after $8000 \mathrm{~J} / \mathrm{m}^{2}$ of accumulated solar energy. Optimization of the reaction volume/volume ratio was achieved by obtaining a minimum $\beta$ factor of 0.27 , which guaranteed turbulent conditions with $\operatorname{Re}>$ 20,000, perfect mixing of particles, and avoided the sedimentation of the catalyst. In addition, this condition is the requirement for the hydrodynamic operation of the pumping system. The overall net energy, i.e., OVRPA, associated with the operation of the two reactors was calculated, and a greater availability of radiant energy was found in the reaction phase space for the OMTP, $412.3 \mathrm{~W} / \mathrm{m}^{3}$ for the CPC (10 tubes) and $653.04 \mathrm{~W} / \mathrm{m}^{3}$ for the OMTP (18 tubes), which is consistent with the experimental results of the degradation of organic pollutants studied. The efficiencies per unit area and volumetric unit of treatment demonstrated the absolute superiority of the OMTP for larger overall volumes, which indicated that the reactor is potentially better for scaling and requires a smaller number of collectors for large volumes of wastewater. Finally, the costs of OMTP was competitive and comparable with conventional CPC solar photoreactor. Further improvements on the performance of the OMTP for water treatment and purification, should include the use of efficient solar responsive photocatalysts.

\section{Acknowledgements}

The authors thank the Universidad de Cartagena (Colombia), Universidad del Valle (Colombia), and Loughborough University (United Kingdom) for funding this publication. Mueses thanks the British Council for the Newton Fund Grant: Researcher Links-BC 030-EDU2016 for funding the stay in the United Kingdom for the development of this publication, COLCIENCIAS (Colombia) for funding doctoral studies, and the Office of the Vice-Head for Research of the University of Cartagena through the

Group Strengthening Project 060-2015 for funding this research.

\section{REFERENCES}

[1] S. Malato, M. I. Maldonado, P. Fernández-Ibáñez, I. Oller, I. Polo, R. Sánchez-Moreno, Decontamination and disinfection of water by solar photocatalysis: The pilot plants of the Plataforma Solar de Almeria, Mat. Sci. Semicon. Proc. 42 (2016) 15-23.

[2] D. Spasiano, R. Marotta, S. Malato, P. Fernandez-Ibañez, I. Di Somma, Solar photocatalysis: Materials, reactors, some commercial, and pre-industrialized applications. A comprehensive approach, Appl. Catal. B: Env. 170-171 (2015) 90-123.

[3] S. Malato, J. Blanco, A. Vidal, D. Alarcón, M. I. Maldonado, J. Cáceres, W. Gernjak, Applied studies in solar photocatalytic detoxification: an overview, Sol. Energy. 75 (2003) 329-336. 
[4] M. N. Chong, B. Jin, C. W. K. Chow, C. Saint, Recent developments in photocatalytic water treatment technology: a review, Wat. Res. 44 (2010) 2997-3027.

[5] N. De la Cruz, R. F. Dantas, J. Giménez, S. Esplugas, Photolysis and $\mathrm{TiO}_{2}$ photocatalysis of the pharmaceutical propranolol: Solar and artificial light, Appl. Catal. B: Env. 130-131 (2013) 249-256.

[6] R. J. Braham, A. T. Harris, Review of Major Design and Scale-up Considerations for Solar Photocatalytic Reactors, Ind. Eng. Chem. Res. 48 (2009) 8890-8905.

[7] J. Colina-Márquez, F. Machuca-Martínez, G. Li Puma, Radiation absorption and optimization of solar photocatalytic reactors for environmental applications, Environ. Sci. Technol. 44 (2010) 5112-5120.

[8] A. E. Cassano, O. M. Alfano, Reaction engineering of suspended solid heterogeneous photocatalytic reactors, Catal. Today. 58 (2000) 167-197.

[9] O. M. Alfano, A. E. Cassano, Advances in Chemical Engineering-Photocatalytic Technologies, Adv. Chem. Eng. 36 (2009) 229-287.

[10] O. Alfano, D. Bahnemann, A. Cassano, R. Dillert, R. Goslich, Photocatalysis in water environments using artificial and solar light, Catal. Today. 58 (2000) 199-230.

[11] V. Romero, O. González, B. Bayarri, P. Marco, J. Giménez, S. Esplugas, Degradation of Metoprolol by photo-Fenton: Comparison of different photoreactors performance, Chem. Eng. J. 283 (2016) 639-648.

[12] R. Dillert, A. E. Cassano, R. Goslich, D. Bahnemann, Large scale studies in solar catalytic wastewater treatment, Catal. Today, 54 (1999) 267-282.

[13] O. A. McLoughlin, P. Fernández Ibáñez, W. Gernjak, S. Malato Rodriguez, L. W. Gill, Photocatalytic disinfection of water using low cost compound parabolic collectors, Sol. Energy. 77 (2004) 625-633.

[14] O. A. McLoughlin, S. C. Kehoe, K. G. McGuigan, E. F. Duffy, F. Al Touati, W. Gernjak, I. Oller Alberola, S. Malato Rodriguez, L.W. Gill, Solar disinfection of contaminated water: a comparison of three small-scale reactors, Sol. Energy. 77 (2004) 657-664.

[15] J. Colina-Márquez, F. Machuca-Martínez, G. Li Puma, Photocatalytic mineralization of commercial herbicides in a pilot-scale solar CPC reactor: Photoreactor modeling and reaction kinetics constants independent of radiation field, Environ. Sci. Technol. 43 (2009) 8953-8960.

[16] M. A. Mueses, F. Machuca-Martinez, G. Li Puma, Effective quantum yield and reaction rate model for evaluation of photocatalytic degradation of water contaminants in heterogeneous pilot-scale solar photoreactors, Chem. Eng. J. 215-216 (2013) 937-947.

[17] G. Sagawe, M. L. Satuf, R. J. Brandi, J. P. Muschner, C. Federer, O. M. Alfano, D. Bahnemann, A. E. Cassano, Analysis of photocatalytic reactors employing the photonic efficiency and the removal efficiency parameters: Degradation of radiation absorbing and nonabsorbing pollutants, Ind. Eng. Chem. Res. 49 (2010) 6898-6908. 
[18] G. Li Puma, Dimensionless Analysis of Photocatalytic Reactors Using Suspended Solid Photocatalyst, Chem. Eng. Res. Des. 83 (2005) 820-826.

[19] A. L. L. Zazueta, H. Destaillats, G. Li Puma, Radiation field modeling and optimization of a compact and modular multi-plate photocatalytic reactor (MPPR) for air/water purification by Monte Carlo method, Chem. Eng. J. 217 (2013) 475-485.

[20] J. Marugán, R. van Grieken, A. E. Cassano, O. M. Alfano, Scaling-up of slurry reactors for the photocatalytic oxidation of cyanide with $\mathrm{TiO} 2$ and silica-supported $\mathrm{TiO} 2$ suspensions, Cat. Today. 144 (2009) 87-93.

[21] J. Marugán, R. van Grieken, C. Pablos, M. L. Satuf, A. E. Cassano, O. M. Alfano, Modeling of a bench-scale photocatalytic reactor for water disinfection from laboratory-scale kinetic data, Chem. Eng. J. 224 (2013) 39-45.

[22] C. S. Zalazar, M. D. Labas, C. A. Martín, R. J. Brandi, A. E. Cassano, Reactor scale-up in AOPs: From laboratory to commercial scale, Water. Sci Technol. 49 (2004) 13-18.

[23] M. L. Satuf, R. J. Brandi, A. E. Cassano, O. M. Alfano, Scaling-up of slurry reactors for the photocatalytic degradation of 4-chlorophenol, Catal. Today. 129 (2007) 110-117.

[24] R. Acosta-Herazo, J. Monterroza-Romero, M. Á. Mueses, F. Machuca-Martínez, G. Li Puma, Coupling the Six Flux Absorption-Scattering Model to the Henyey-Greenstein scattering phase function: Evaluation and optimization of radiation absorption in solar heterogeneous photoreactors, Chem. Eng. J. 302 (2016) 86-96.

[25] G. C. Roda, F. Santarelli, A rational approach to the design of photocatalytic reactors, Ind. Eng. Chem. Res. 46 (2007) 7637-7644.

[26] F. Machuca-Martínez, M. Á. Mueses, J. Colina-Márquez, G. Li Puma, Photocatalytic reactor modeling, in: J. Schneider, D. Bahnemann, J. Ye, G. Li Puma, D. D. Dionysiou (Eds.), Photocatalysis: fundamentals and perspectives, Royal Society of Chemistry, London 2016, pp. 388424.

[27] N. Suaterna-Ortíz, C. Insignares-Rendón, M. Mueses, R. Camargo, Pilot scale heterogeneous solar photodegradation of 4-chlorophenol in a cylindrical parabolic composed reactor (CPC), Informacion Tecnologica. 23 (2012) 13-24.

[28] M. L. Satuf, R. J. Brandi, A. E. Cassano, O. M. Alfano, Experimental Method to Evaluate the Optical Properties of Aqueous Titanium Dioxide Suspensions, Ind. Eng. Chem. Res. 44 (2005) 6643-6649.

[29] M. I. Polo-López, M. Castro-Alférez, I. Oller, P. Fernández-Ibáñez, Assessment of solar photoFenton, photocatalysis, and $\mathrm{H}_{2} \mathrm{O}_{2}$ for removal of phytopathogen fungi spores in synthetic and real effluents of urban wastewater, Chem. Eng. J. 257 (2014) 122-130.

[30] K. Villa, X. Domènech, S. Malato, M. I. Maldonado, J. Peral, Heterogeneous photocatalytic hydrogen generation in a solar pilot plant, Int. J. Hydrogen Energ. 38 (2013) 12718-12724. 
[31] F. Sciacca, J. A. Rengifo-Herrera, J. Wéthé, C. Pulgarin, Solar disinfection of wild Salmonella sp. in natural water with a $18 \mathrm{~L} \mathrm{CPC}$ photoreactor: Detrimental effect of non-sterile storage of treated water, Sol. Energy. 85 (2011) 1399-1408.

[32] M. Kositzi, I. Poulios, S. Malato, J. Caceres, A. Campos, Solar photocatalytic treatment of synthetic municipal wastewater, Wat. Res. 38 (2004) 1147-54.

[33] T. Zhang, T. Oyama, A. Aoshima, H. Hidaka, J. Zhao, N. Serpone, Photooxidative N-demethylation of methylene blue in aqueous TiO2 dispersions under UV irradiation, J. Photochem. Photobiol., A: Chem. 140 (2001) 163-172.

[34] W. S. Kuo, P. H. Ho, Solar photocatalytic decolorization of methylene blue in water, Chemosphere. 45 (2001) 77-83.

[35] M. A. Rauf, M. A. Meetani, S. Hisaindee, An overview on the photocatalytic degradation of azo dyes in the presence of TiO2 doped with selective transition metals, Desalination. 276 (2001) 13-27.

[36] K. Rajeshwar, M. E. Osugi, W. Chanmanee, C. R. Chenthamarakshan, R. V. B. Zanoni, P. Kajitvichyanukul, R. Krishnan-Ayer, Heterogeneous photocatalytic treatment of organic dyes in air and aqueous media, J. Photochem. Photobiol., C: Photochem. Rev. 9 (2008) 171-192.

[37] D. Curcó, S. Malato, J. Blanco, J. Giménez, P. Marco, Photocatalytic degradation of phenol: Comparison between pilot-plant-scale and laboratory results, Sol. Energy. 56 (1996) 387-400.

[38] S. Ahmed, M. G. Rasul, W. N. Martens, R. Brown, M. A. Hashib, Heterogeneous photocatalytic degradation of phenols in wastewater: A review on current status and developments, Desalination. 261 (2010) 3-18.

[39] L. Mino, A. Zecchina, G. Martra, A. M. Rossi, G. Spoto, A surface science approach to $\mathrm{TiO}_{2} \mathrm{P} 25$ photocatalysis: An in situ FTIR study of phenol photodegradation at controlled water coverages from sub-monolayer to multilayer, Appl. Catal. B: Environ. 196 (2016) 135-141.

[40] A. Shet, S. K. Vidya, Solar light mediated photocatalytic degradation of phenol using Ag core TiO2 shell (Ag@TiO2) nanoparticles in batch and fluidized bed reactor, Sol. Energy. 127 (2016) 6778.

[41] C. S. Zalazar, R. L. Romero, C. A. Martín, A. E. Cassano, Photocatalytic intrinsic reaction kinetics I: Mineralization of dichloroacetic acid, Chem. Eng. Sci. 60 (2005) 5240-5254.

[42] H. L. Otálvaro-Marín, M. A. Mueses, F. Machuca-Martínez, Boundary layer of photon absorption applied to heterogeneous photocatalytic solar flat plate reactor design, Int. J. Photoenergy. 2014 (2014) https://doi.org/10.1155/2014/930439 



\title{
A Novel Prototype Offset Multi Tubular Photoreactor (OMTP) for Solar Photocatalytic Degradation of Water Contaminants
}

\author{
Karen Sofía Ochoa-Gutiérrez ${ }^{1}$, Erick Tabares-Aguilar ${ }^{1}$, Miguel Ángel Mueses ${ }^{1}$, Fiderman Machuca-Martínez ${ }^{2}$, and \\ Gianluca Li Puma ${ }^{3}$ \\ ${ }^{1}$ Photocatalysis \& Solar Photoreactors Engineering, Chemical Engineering Program, Universidad de Cartagena \\ A.A. 1382 - Postal 195, Cartagena-Colombia \\ ${ }^{2}$ GAOX Research Group, School of Chemical Engineering, Universidad del Valle, A. A. 25360, Cali-Colombia \\ ${ }^{3}$ Environmental Nanocatalysis \& Photoreaction Engineering, Department of Chemical Engineering, Loughborough \\ University, LE11 3TU, Loughborough, United Kingdom \\ Corresponding Author: fiderman.machuca@correounivalle.edu.co
}

E-Mails:

Karen Sofía Ochoa-Gutiérrez: Karenog18@gmail.com

Erik Tabares-Aguilar: tabares0207@gmail.com

Miguel Angel Mueses: mmueses@unicartagena.edu.co

Gianluca Li Puma: G.Lipuma@1boro.ac.uk

*Corresponding Author: Fiderman Machuca-Martínez: fiderman.machuca@ correounivalle.edu.co 


\title{
A Novel Prototype Offset Multi Tubular Photoreactor (OMTP) for Solar Photocatalytic Degradation of Water Contaminants
}

\author{
Karen Sofía Ochoa-Gutiérrez ${ }^{1}$, Erick Tabares-Aguilar ${ }^{1}$, Miguel Ángel Mueses ${ }^{1}$, Fiderman Machuca-Martínez ${ }^{2}$, and \\ Gianluca Li Puma ${ }^{3}$ \\ ${ }^{1}$ Photocatalysis \& Solar Photoreactors Engineering, Chemical Engineering Program, Universidad de Cartagena \\ A.A. 1382 - Postal 195, Cartagena-Colombia \\ ${ }^{2}$ GAOX Research Group, School of Chemical Engineering, Universidad del Valle, A. A. 25360, Cali-Colombia \\ ${ }^{3}$ Environmental Nanocatalysis \& Photoreaction Engineering, Department of Chemical Engineering, Loughborough \\ University, LE11 3TU, Loughborough, United Kingdom \\ Corresponding Author: fiderman.machuca@correounivalle.edu.co
}

\begin{abstract}
The design and operation of a new solar photoreactor prototype named Offset Multi Tubular Photoreactor (OMTP) is presented. The OMTP advances over the compound parabolic collector (CPC) photoreactor, which is one of the most efficient design for large-scale solar detoxification of water and wastewater. The OMTP design is based on a simple modification of the common CPC and included a supplementary set of tubes in the space occupied by the axes of intersection of the CPC reflective involutes. This new reactor configuration increased the irradiated reactor volume by $79 \%$ and the fluid residence time by up to 1.8 fold in comparison to the CPC, for the same solar irradiated area (footprint). The model parameters used for comparing and scaling the OMPT and CPC were $\beta$ (reactor volume/total volume), $\alpha$ (area of absorption/total volume), $\alpha_{g}$ (physical area/total volume), degradation efficiency $\eta_{\alpha}$ per unit area, and the operating volume. The total solar energy absorbed in the reactors $\left(1.74 \mathrm{~m}^{2}\right.$ footprint $)$ was $15.17 \mathrm{~W}$ for the $\mathrm{CPC}$ and $21.86 \mathrm{~W}$ for the OMTP, which represents an overall gain of $44 \%$ for the latter. The performance of the OMTP and CPC were compared at the same value of solar exposure $\beta$ of 0.3 with optimal photocatalyst loading of $0.25 \mathrm{~g} / \mathrm{L}$ titanium dioxide $\left(\mathrm{TiO}_{2} \mathrm{P} 25\right)$. The degradation efficiencies of methylene blue, dichloroacetic acid, 4-chlorophenol (120 ppm initial concentration) in the OMTP were up to $81 \%$, $125 \%, 118 \%$ and $242 \%$ higher, respectively, in comparison to the CPC after $8000 \mathrm{~J} / \mathrm{m}^{2}$ of accumulated solar energy. The OMTP should outperform the CPC in environmental and renewable energy applications of solar heterogeneous photocatalysis.
\end{abstract}

Keywords: Solar photocatalysis, OMTP and CPC photocatalytic reactor, $\mathrm{TiO}_{2}-\mathrm{P} 25$, Six Flux Model-HG 


\section{INTRODUCTION}

The efficient utilization of renewable solar energy is essential for the development of sustainable processes for the production of clean energy, biofuels, hydrogen, for environmental clean-up, water disinfection and for the exploitation of self-cleaning surfaces. Among these processes, solar photocatalysis has attracted industrial interest as a sustainable process for the mitigation of the environmental effects associated with water pollution [1]. Different applications of photocatalysis for the degradation and mineralization of water contaminants, such as pesticides, herbicides, dyes, emerging pollutants, phenols, and halogenated compounds, have been demonstrated at pilot-scale using solar radiation and commercial catalysts [2-5]. The most common pilot-scale solar photoreactors include parabolic trough reactors (PTRs), flat plate reactors (FPRs), Heliomans reactors (HLMR), double-skin sheet reactors (DSSRs), and compound parabolic collector (CPC) reactors [6]. Undoubtedly, the most widely used commercial solar reactor is the CPC, since it combines efficient capture of solar radiation (Figure 1) with favorable hydrodynamics resulting in effective water treatment.

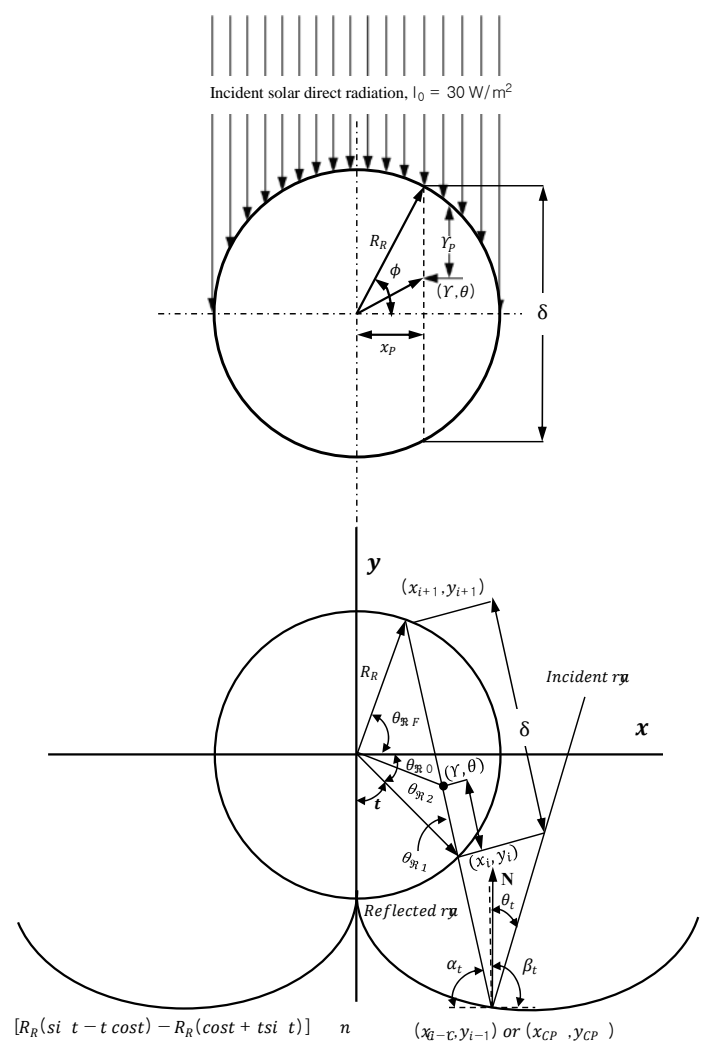

Figure 1. Geometric schematic of a CPC reactor with direct incident solar radiation of $30 \mathrm{~W} / \mathrm{m}^{2}$ (adapted from [7]) 
The CPC is essentially a tubular reactor with two highly polished, semi-involute, aluminium reflectors located at the bottom of the tube. This photoreactor is usually a static device inclined to the sun by an angle which maximize the absorption of solar light [1]. Its optical advantage lies in the redirection of both direct and diffuse solar light by the reflectors without excessive thermal effects on the water that flows inside the tube. The hydrodynamic advantage is presented by operation under turbulent flows with low power consumption costs, which ensure perfect lateral mixing and a homogeneous suspension of the catalyst particles. Furthermore, its closed configuration avoids the evaporation of volatile contaminants [2, 6, 8-15]. The materials used for its construction are in general inexpensive such as PVC for the fittings and Perspex for the tubes although the highly polished aluminium for the reflectors and the borosilicate glass as replacement for the Perspex tubes, have a relatively higher cost.

The design and optimization of the CPC photoreactor for water treatment has been performed using mathematical models that describe the incident solar radiation, the absorption and scattering of photons, the reaction kinetics, the hydrodynamics and the quantum efficiencies [8, 11, 16-25]. The models allow the selection of the optimal tube diameter and suspended catalyst concentration $[6,7,24]$, the evaluation of the type of semiconductor materials and the flow hydrodynamics [25]. Despite the favorable properties of the CPC photoreactor its design presents some fundamental limitations in commercial terms including low operating volumes of treatment in relation to the solar footprint occupied by CPC arrays and the apparent difficulty in scaling-up to large bore diameters due to the fragility of the pipe and the requirement for larger size end connections which increase costs and are prone to leaking.

In this study, the conceptual design and evaluation of a new prototype of an offset multi tubular solar photoreactor (OMTP), which mitigates the limitation of CPC and that can be adopted for industrial wastewater treatment is presented. The basic principle of this design is based on the removal of the costly CPC involute reflectors and in the introduction of a further set of tubes, which significantly increase the total reactor volume in relation to the solar footprint. The performance of the OMTP was evaluated and benchmarked against the CPC for the removal of methylene blue (MB), dichloroacetic acid (DCA), 4chlorophenol (4-CP), and phenol in water.

\section{DESIGN OF THE NEW SOLAR PHOTOREACTOR PROTOTYPE}

\subsection{Photoreactor design}

Figure 2 schematically shows the configuration of this new prototype, which is named the Offset Multi Tubular Photoreactor (OMTP). The design of the OMTP solar photoreactor prototype eliminates the use 
of costly parabolic involutes of conventional CPCs (Figure 2a) and introduces a further set of offset parallel tubes, with their axes located at the contact points of the CPC involutes, in the space occupied by the involutes. An optional polished aluminium flat reflector located at the bottom of the tubes could be fitted to improve the capture of solar light, although this is not an essential element.

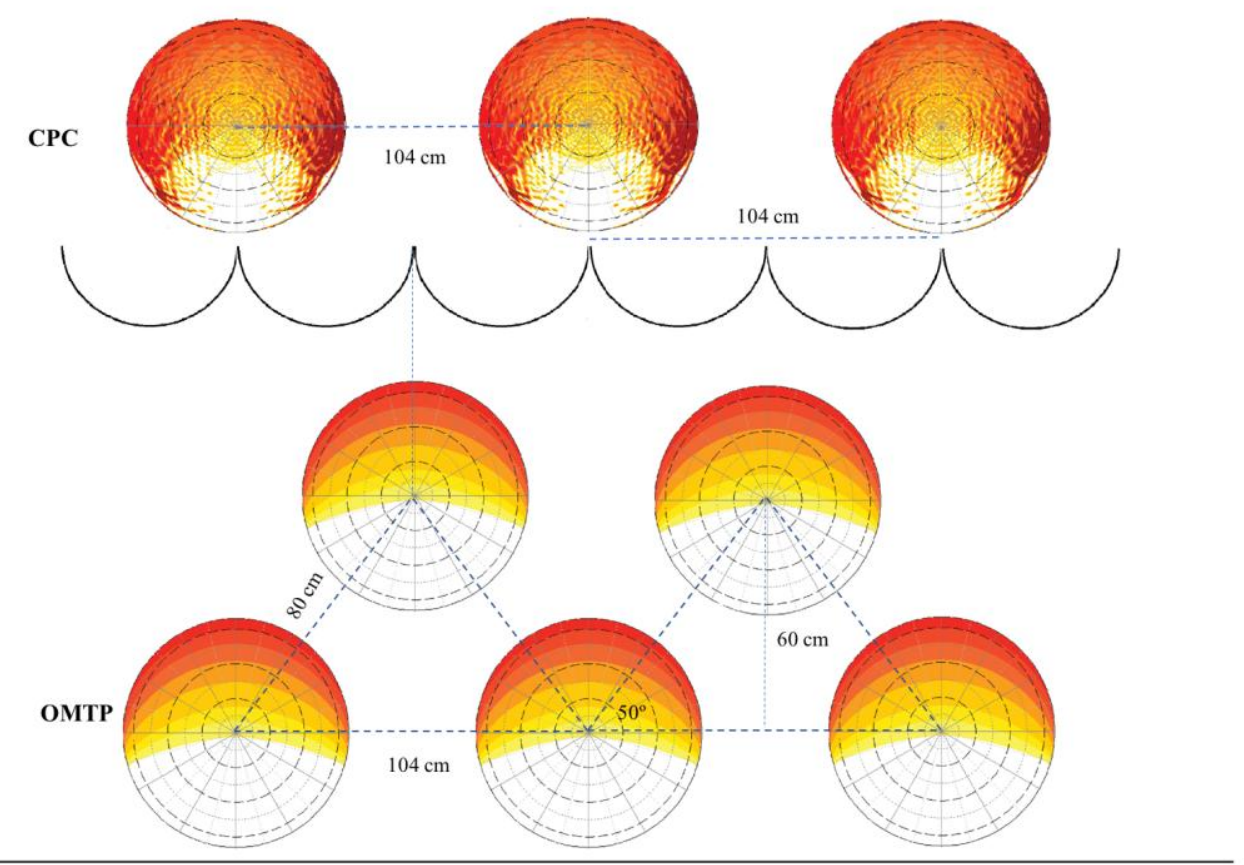

Figure 2. Distribution of tubes in a conventional CPC reactor (up) (adapted from [7]) and in an OMTP configuration (down)

The fundamental principle of this new design lies in the inclusion of $(2 n-1)$ set of reaction tubes, located over the vertices of isosceles triangle. The separations between tubes are showed in the Figure 2, which in comparison to a conventional CPC of $n$ tubes, significantly increase the total fluid residence time and operating volume of the reactor, while maintaining the same physical area (footprint) occupied by the solar collector (Figure 3). The further set of $(n-1)$ tubes in the OMTP is offset in comparison to the $n$ set of CPC, which also facilitate tubes connections. Table 1 compares the specifications of the OMTP photoreactor with those of a CPC, which were evaluated in this study. 
Table 1. Specifications of CPC reactor and OMTP.

\begin{tabular}{lll}
\hline Type of Reactor & CPC & OMTP \\
\hline Collector surface area* $\left(\mathrm{m}^{2}\right)$ & 1.74 & 1.74 \\
Collector length $(\mathrm{m})$ & 3.0 & 3.0 \\
Collector width $(\mathrm{m})$ & 0.58 & 0.58 \\
Collector height $(\mathrm{m})$ & 0.12 & 0.16 \\
Collector material & Zinc & Zinc \\
Tube material & Borosilicate & Borosilicate \\
Tube external diameter $(\mathrm{m})$ & 0.032 & 0.032 \\
Tube thickness (m) & 0.0014 & 0.0014 \\
Exposed tube length $(\mathrm{m})$ & 1.2 & 1.2 \\
Number of tubes & 10 & 18 \\
Absorption surface area** $\left(\mathrm{m}^{2}\right)$ & 1.2 & 1.1 \\
Exposed reactor volume $(\mathrm{L})$ & 8.04 & 14.46 \\
Involute material & Aluminum & ---- \\
Involute reflector angle & $90^{\circ}$ & ---- \\
Involute reflectivity & 0.85 & ----
\end{tabular}

* The collector area represents the space occupied by the reactor structural metal box **Represents the total area of the tubes exposed to sunlight 


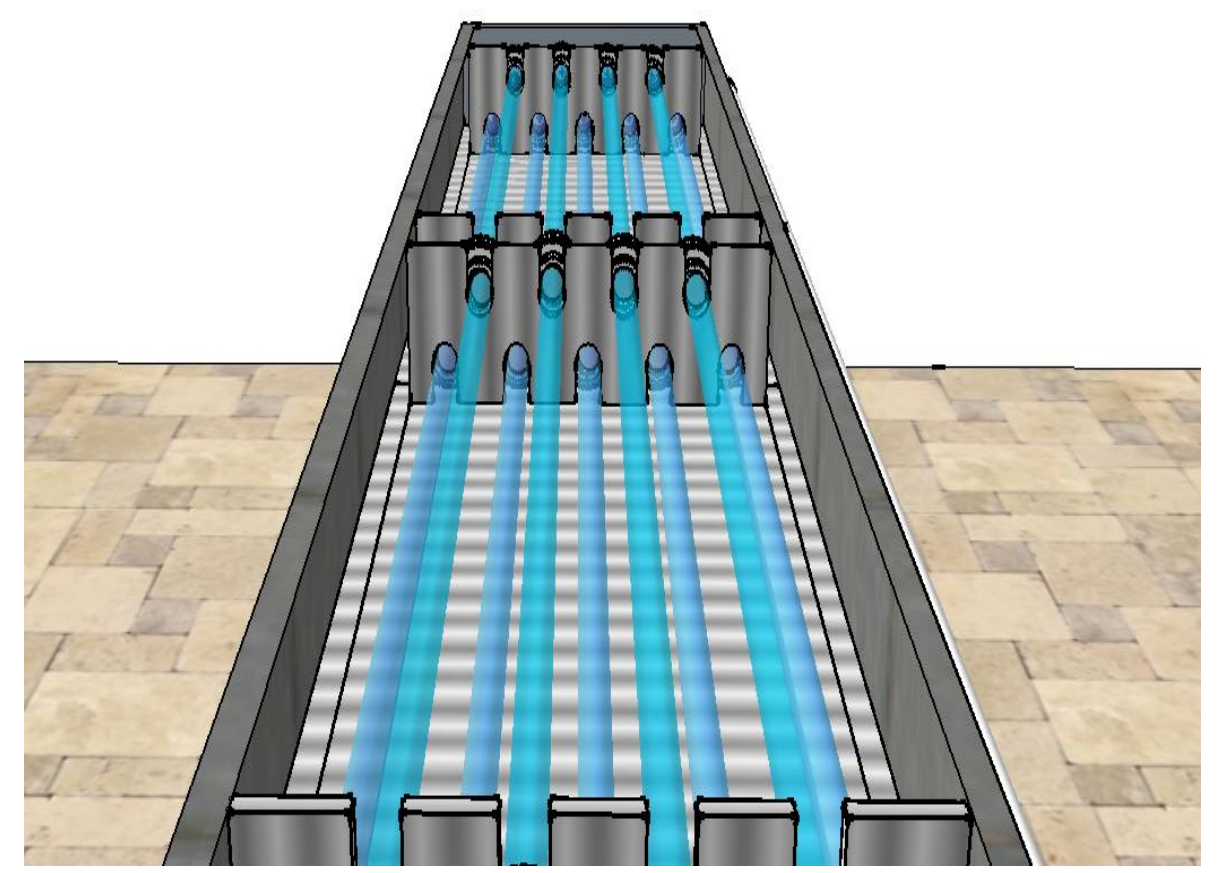

Figure 3. Proposed schematic design for the OMTP (design simulation using Sketchup®)

\subsection{Photoreactor performance parameters}

The design of an efficient photocatalytic reactor begins with its reactor geometry since this implicitly influences the photons paths, the optical thickness, and the optical limiting layer of the reactor [26]. In addition, the performance of a solar photoreactor is affected by the intensity of the incident radiation (direct and diffuse solar radiation), which is a function of the geographical latitude, session of year, hour of the day and the atmospheric conditions.

For an adequate comparison of the performance of solar photoreactors under variable solar conditions, the following scaling parameters have been considered:

$$
\begin{aligned}
& =\frac{S_{T}}{V_{R}} \\
& g=\frac{A_{T, \text { Collector }}}{V_{T}} \\
& =\frac{V_{R}}{V_{T}}
\end{aligned}
$$


$t_{W S}=\frac{1}{I_{G, U V}^{0}} I_{G, U V}(t)$

$\eta_{\alpha}=\frac{1}{\alpha}\left|\frac{C_{T O C}\left(t_{W S, 0}\right)-C_{T O C}\left(t_{W S, f}\right)}{C_{T O C}\left(t_{W S, 0}\right)}\right|$

$V_{T}=V_{R}+V_{D Z}$

where $\alpha$ is the ratio of the surface area $\left(S_{T}\right)$ to the volume $\left(V_{R}\right)$ of the transparent reactor tubes exposed to solar light; $\alpha_{g}$ is the ratio of the total area occupied by the collector structure $\left(A_{T, \text { Collector }}\right)$ and the total operating liquid volume $\left(V_{T}\right) ; \beta$ is the ratio of reactor volume to total liquid volume; $t_{W S}$ is the standard treatment time, $I_{G, U V}^{0}$ is the standard global average irradiance [3]; $I_{G, U V}(t)$ is the incident UV radiation at time $t ; \eta_{\alpha}$ is the degradation efficiency per unit area per unit treatment volume; $C_{T O C}\left(t_{W S, 0}\right)$ is the initial TOC concentration of the contaminant in the water at the initial time; $C_{T O C}\left(t_{W S, f}\right)$ is the final TOC concentration of the contaminant after a total time in which solar energy has been accumulated; and $V_{D Z}$ is the volume of the dark zone of the reactor usually also comprising a recycling system. The standard treatment time considers the variations in solar irradiance due to atmospheric changes.

\section{METHODOLOGY}

The common water contaminants phenol, dichloroacetic acid (DCA), 4-chlorophneol (4-CP) (all 99.9\% analytical grade from Merck $®$ ), and commercial-grade Methylene Blue (MB) typically used for kinetic studies in large-scale photocatalytic reactors [2] were used to evaluate the performance of the OMTP with respect to the CPC. Evonik-Degussa $\mathrm{TiO}_{2}-\mathrm{P} 25$ was used as the suspended catalyst, and commercial $\mathrm{HCl}$ $(0.2 \mathrm{M})$ was used to change the $\mathrm{pH}$ of the water. The overall concentration of the water contaminants was monitored with a total organic carbon (TOC-V CPH Shimadzu) and a UV-vis spectrophotometer (Labomed Spectro UV-2650). The instantaneous and accumulated solar radiation (Figure S1, Supporting Information) was monitored with a Delta Ohm 210.2 radiometer with an LP-UVB probe (300-360 nm) and the $\mathrm{pH}$ was measured with a Consort $\mathrm{pH}-$ meter $\mathrm{C} 931$.

The hydrodynamic performance was adjusted using the $\beta$ parameter (Eq. 3) with the volumetric flow in turbulent regime (Reynolds number $>20,000$ ) to avoid sedimentation of the catalyst. One inch PVC fittings were used to connect the borosilicate tubes. The water was circulated with a IWAKI-VMD40RLXT magnetic pump with a nominal power of $0.5 \mathrm{HP}$ and $35 \mathrm{~L} / \mathrm{min}$ maximum flowrate. 


\subsection{Experimental Evaluation of the OMTP Using Methylene Blue}

The removal of MB (10 ppm) by adsorption was evaluated with four catalyst concentrations $(0.20,0.25$, 0.30 , and $0.35 \mathrm{~g} / \mathrm{L})$ at natural $\mathrm{pH}(7.45 \pm 0.18)$. The tests were done using $100 \mathrm{ml}$ samples, which were continuously agitated in the dark for 4 hours in conical flasks. Aliquots were collected from these every 15 minutes to measure the residual concentration of MB by UV-Vis spectrophotometry.

The photocatalytic degradation of MB in the OMTP, at an initial concentration of $10 \mathrm{ppm}$ was evaluated at the catalyst concentrations $(0.00,0.20,0.25,0.30,0.35 \mathrm{~g} / \mathrm{L})$, at a volumetric flow rate of $24 \mathrm{~L} / \mathrm{min}$ and using a $\beta$ factor of $0.3\left(\mathrm{~V}_{\mathrm{R}}=9.7 \mathrm{~L}\right.$, see Table 1$)$. The range of catalyst concentrations investigated was established considering the optimization of tubular solar photoreactors which determined that for 32-mm diameter borosilicate glass tubes, the optimal operating concentration of $\mathrm{TiO}_{2}-\mathrm{P} 25$ should be between 0.20 and $0.40 \mathrm{~g} / \mathrm{L}[16]$.

The reactor set-up comprised the OMTP and the water recycle system, which included a stirred tank, where the solutions were made and samples were collected, a centrifugal pump and two control valves to control the recirculation flowrate.

In a typical experiment, the stirred tank was initially loaded with $29 \mathrm{~L}$ of tap water and the photocatalyst was added to form a slurry suspension and circulated in the reactor system for $10 \mathrm{~min}$. Then, $1 \mathrm{~L}$ of contaminant aqueous solution, at the required concentration, was added in the reactor system and the suspension was recirculated under darkness for $30 \mathrm{~min}$ to establish adsorption/desorption equilibrium conditions. Then a sample was taken and the reactor was exposed to solar light at $\left(\mathrm{t}_{\mathrm{sw}}=0\right)$. In situ measurements of dissolved oxygen, $\mathrm{pH}$ and temperature were monitored during the experiments (Table S1, Supporting Information). The reactor was exposed to solar light until a cumulative UV-B total energy of $8000 \mathrm{~J} / \mathrm{m}^{2}$ was reached. Samples were collected every 1000 units of accumulated energy, they were filtered, centrifuged, and analyzed by UV-Vis spectrophotometry. The same procedure was followed to monitor the contaminants degradation in the CPC reactor under solar light.

\subsection{Comparison of OMTP and CPC in the Degradation of Organic Pollutants}

The results of the degradation of phenol, DCA, and 4-CP were used to compare the performance of the OMTP and CPC photoreactors on a solar pilot scale with suspended $\mathrm{TiO}_{2}-\mathrm{P} 25$, at catalyst concentrations of $0.10 \mathrm{~g} / \mathrm{L}$ for phenol, $0.35 \mathrm{~g} / \mathrm{L}$ for DCA, and $0.5 \mathrm{~g} / \mathrm{L}$ for $4-\mathrm{CP}$. These values of catalyst concentrations were optimized in previous investigations carried out in a CPC reactor operated under identical 
experiment conditions and total incident solar radiation [16]. The initial $\mathrm{pH}$ of the water was 3.0 for phenol, 3.2 for DCA, and 3.5 for 4-CP, as recommended by [27]. The initial concentration of each contaminant in the water was 120 and $60 \mathrm{ppm}[26]$.

The $\beta$ factor in the CPC and OMPT reactor systems was held constant at 0.3 , and the volumetric flow rate in both systems was set at $24 \mathrm{~L} / \mathrm{min}$ to ensure a turbulent flow regime $(\operatorname{Re}=21140$ ) and uniform suspensions of the catalyst. In such way, the number of passes of the water through the reactors were the same, allowing a direct comparison of the two reactor systems. The physical area of the collector was

constant (one reactor module, $A_{T, \text { Collector }}=1.74 \mathrm{~m}^{2}$ ), while the total operating volumes were $36 \mathrm{~L}$ for the $\mathrm{CPC}$ and $65 \mathrm{~L}$ for the OMTP, respectively.

Continuous air bubbling in the recirculation stirred tank was provided to maintain the water under oxygen saturation conditions during the oxidation reaction which was carried out at the operating temperature of $33^{\circ} \mathrm{C} \pm 0.3$. The effect of molecular adsorption or direct photolysis of the contaminants tested were negligible and did not directly affect the photocatalytic process as previously shown [16].

The operating procedure for the solar heterogeneous photocatalysis tests were as described for the MB with sample collected every 1600 units of accumulated energy up to $8000 \mathrm{~J} / \mathrm{m}^{2}$. The samples after filtration and centrifugation were analyzed by TOC.

\subsection{Mathematical Evaluation of OMTP and CPC Performance}

The formulations of the modeling equations of the OMTP and CPC reactors are based on the generalized methodology (Fig. 4) for heterogeneous pilot-scale solar reactors, $\mathrm{TiO}_{2}-\mathrm{P} 25$ and natural solar radiation proposed by [16]. 


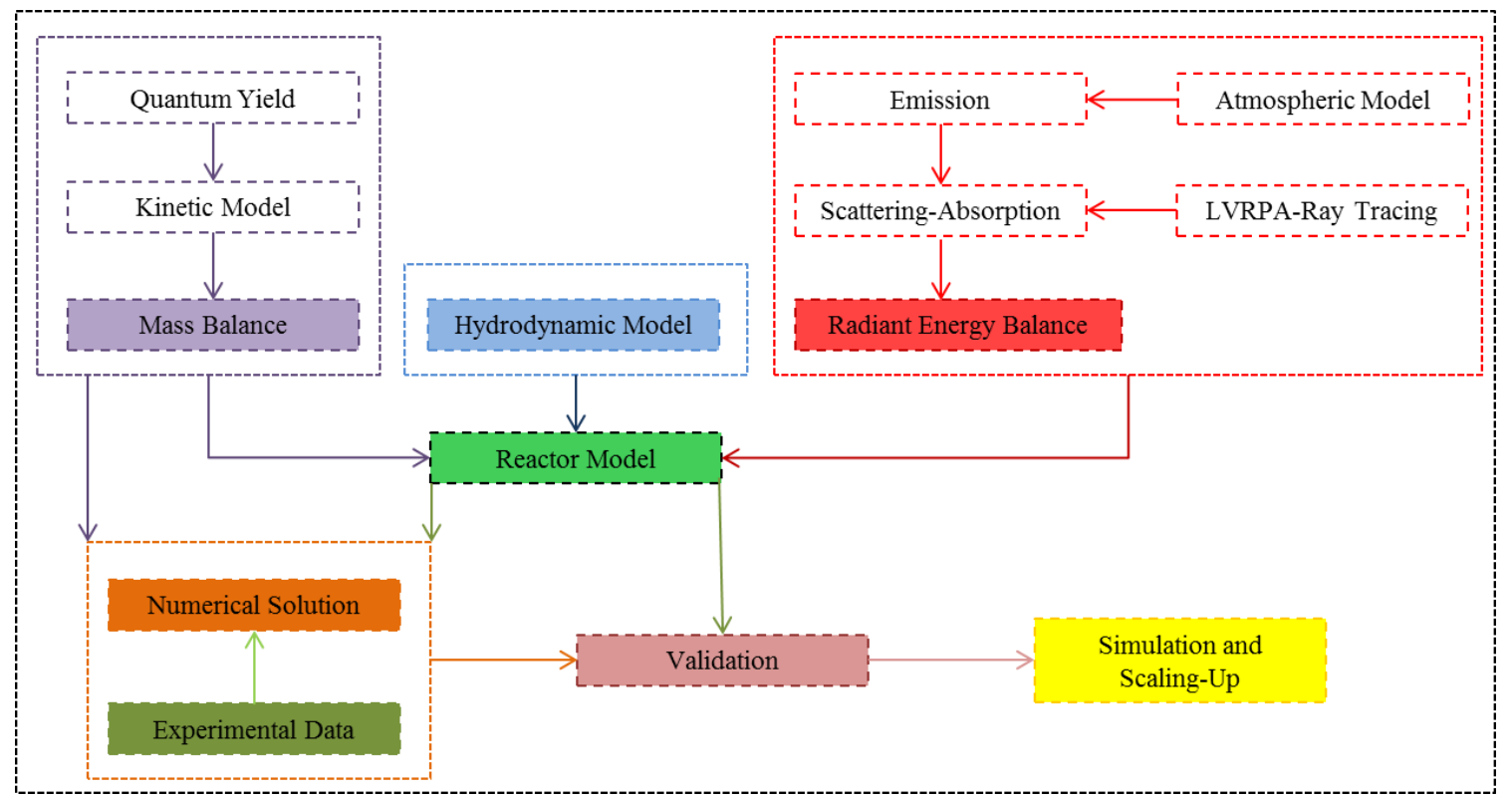

Figure 4. Methodological structure of the model. Adapted from [16].

Both OMTP and CPC reactors were modeled as flow-through reactors with total recycling, thus, the material balance could be described as an integral-differential equation as a function of the cumulative incident solar energy $\xi_{A E}$, the average total concentration of the contaminant, and the generalized kinetic model for the heterogeneous photocatalytic degradation of organic contaminants in the presence of $\mathrm{TiO}_{2}$ P25, under the concept of constant isotropic global parameters throughout the reactor volume $\left(\Phi_{g}\right.$ is quantum yield (mol/Einstein); $\hat{E}_{g\left(\lambda \rightarrow \lambda^{\prime}\right)}^{a}$ is Effective Volumetric Rate of Energy Absorption, VREA $\left(\right.$ Einstein $\left./ \mathrm{s} . \mathrm{m}^{3}\right) ; \alpha_{1}$ is the kinetic reaction rate constant $\left(\mathrm{mol} / \mathrm{m}^{2} \cdot \mathrm{s}\right) ; \kappa_{P}$ is the constant of particle $\left(\mathrm{m}^{3} / \mathrm{m}^{2}\right)$ and $k_{A}^{L-H}$ is absorption constant of the L-H model $\left.\left(\mathrm{m}^{3} / \mathrm{mol}\right)\right)$ [16]:

$$
\begin{aligned}
& \frac{d C_{i}}{d \xi_{A E}}=\frac{1}{\xi_{t}}\left(\frac{1}{V_{T}}\right) \int_{V_{R}}\left(-r_{i}\right) d v=-2 \beta \frac{\alpha_{1}}{\kappa_{P}}\left[-1+\sqrt{1+\frac{\kappa_{P}}{\alpha_{1}} \Phi_{g} \hat{E}_{g\left(\lambda \rightarrow \lambda^{\prime}\right)}^{a}}\right] \frac{k_{A}^{L-H} c_{i}}{1+k_{A}^{L-H} c_{i}} \\
& \xi_{t}=\frac{1}{\left(d \xi_{A E} / d t_{S W}\right)}
\end{aligned}
$$

where $\xi_{A E}$ is the slope of the experimental data relationship of the cumulative incident solar radiation vs. time for each experimental test, and $\xi_{t}$ is the inverse slope of the relationship of the incident radiation and standard treatment time. The $\xi_{t}$ function is proposed to account for the fluctuation of the incident solar irradiance due to atmospheric phenomena and time of the day. The model parameters in equation (7) have been reported in [16]. 
The incident solar radiation $I_{0}$ arriving on the reactors was modeled using the methodology reported by [15], which considers constant solar radiation in the longitudinal axis of the tubular reactors, corrected for the geographic position and time of the year of Cartagena-Colombia $\left(10^{\circ} 25^{\prime} 25^{\prime \prime} \mathrm{N}\right.$. L $\left.-75^{\circ} 31^{\prime} 31^{\prime \prime} \mathrm{W}\right)$. At this latitude the upper tubes did not produced shadows to the lower tubes during the experimental time. The local volumetric rate of photon absorption (LVRPA), which describes the effect of photon absorption and scattering in the reactor, was quantified using the SFM-HG model [24]:

$$
\frac{L V R P A}{I_{0}}=\frac{1}{\lambda_{\omega_{\text {corr }}} \omega_{\text {corr }}(1-\gamma)}\left[\omega_{\text {corr }}-1+\sqrt{1-\omega_{\text {corr }}^{2}} e^{\frac{-x}{\lambda_{\omega_{c o r r}}}}+\gamma\left(\omega_{\text {corr }}-1-\sqrt{1-\omega_{\text {corr }}^{2}} e^{\frac{x}{\lambda_{\text {corr }}}}\right)\right]
$$

The values of the absorption $(\kappa)$ and scattering $(\sigma)$ coefficients were as those in [28] and the probabilities of forward, backward and side scattering for $\mathrm{TiO}_{2}-\mathrm{P} 25$ were $p_{f}=0.754, p_{b}=0.133$ and $p_{s}=0.027$ [24].

The model parameters depend on the ray pathlenghs $\delta$ (Figure 1), which for tubular and CPC reactors were evaluated using the methodology of [7] and [15].

Finally, the hydrodynamic performance of the reactor was that of perfectly mixed batch reactor due to the large circulation ratio and small conversion per pass. The mass balance of the batch reactor (Eq. 7) is an equation in grouped parameters, independent of the geometrical coordinates. Therefore, the properties of the reaction suspension (fluid + suspended particles) were assumed as a pseudo-homogeneous mixture. The parameters in the mass balance were modeled as constant isotropic global parameters and in consequence a hydrodynamic model became redundant.

\section{RESULTS AND DISCUSSION}

\subsection{Evaluation of the optical and hydrodynamic performance of the reactor}

The optical comparison of the OMTP with respect to the CPC was quantified using the overall volumetric rate of photon absorption (OVRPA) [16] (Eq. 10).

$O V R P A=\frac{1}{V_{R}} \int_{V_{R}} L V R P A(V) d V$ 
The reactor to total volume ratio $\beta$, is a scaling parameter that is indirectly related to the performance of the pumping system. In order to maintain optimal pump operation (suction and discharge), turbulent flow conditions and uniform suspension of the catalyst [12], the minimum $\beta$ ratio was 0.27 . The reactor systems were therefore operated with an overshoot factor of $10 \%(\beta=0.3)$ and with total volumes of $32 \mathrm{~L}$ for the CPC and $58 \mathrm{~L}$ for the OMTP.

Figure 5 shows the LVRPA distribution on a cross section of the CPC and OMPT calculated using the SFM-HG model and $0.25 \mathrm{~g} / \mathrm{L} \mathrm{TiO}_{2}-\mathrm{P} 25$, on a clear sunny day. The equivalent values of the OVRPA were $1887.94 \mathrm{~W} / \mathrm{m}^{3}$ for the CPC and $1511.07 \mathrm{~W} / \mathrm{m}^{3}$ for the OMTP, and the total solar power absorbed in the CPC and OMPT collectors were $15.17 \mathrm{~W}$ for the CPC $\left(1887.94 \mathrm{~W} / \mathrm{m}^{3} \times 0.00804 \mathrm{~m}^{3}\right)$ and $21.86 \mathrm{~W}$ for the OMTP $\left(1511.07 \mathrm{~W} / \mathrm{m}^{3} \times 0.01446 \mathrm{~m}^{3}\right)$, representing an optical gain of $44 \%$ for the latter. The OMTP advantage is reflected in increased system degradation efficiencies and larger operation volumes $\left(V_{T}\right)$. These values are consistent with previous reports [24].
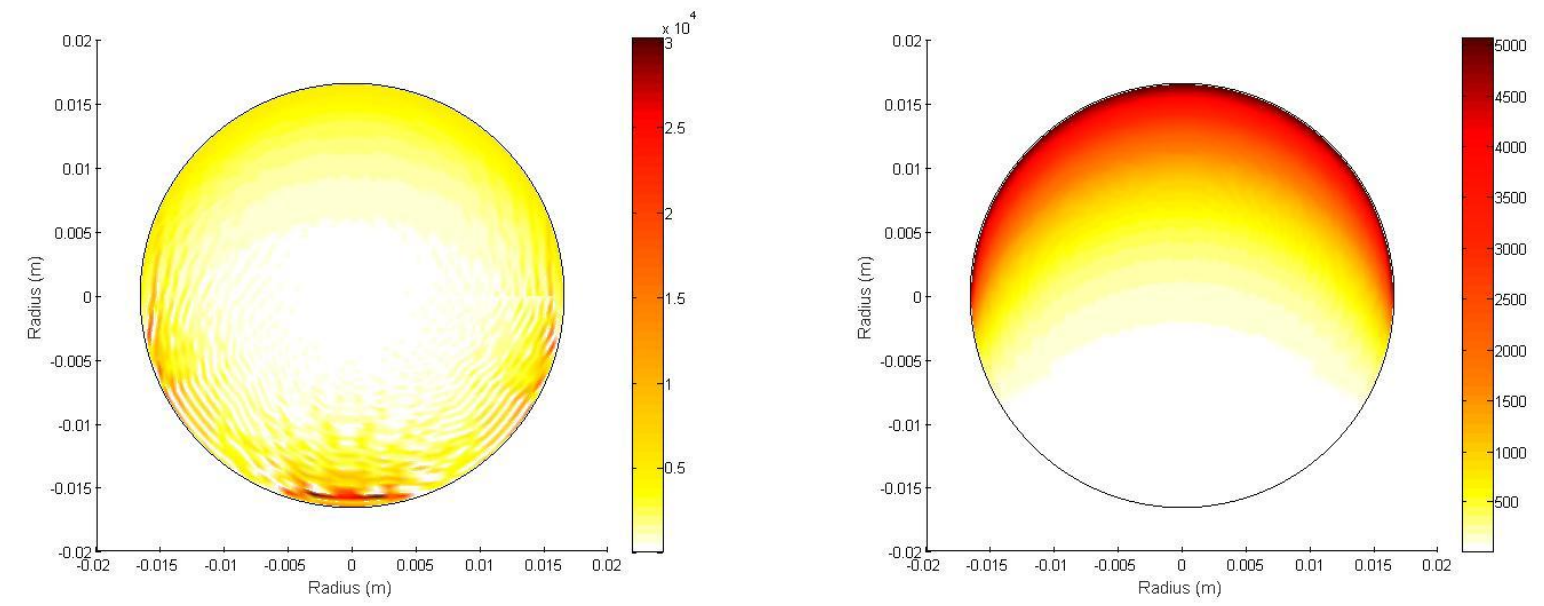

a

Figure 5. Distribution of LVRPA using SFM-HG: a) CPC reactor and b) OMTP for a $\mathrm{TiO}_{2}-\mathrm{P} 25$ catalyst loading of $0.25 \mathrm{~g} / \mathrm{L}$.

\subsection{OMTP and CPC footprints and process economics}

The primary limitations of the CPC reactor are the treatment volume capacity and the area occupied by each collector module, particularly considering that large exposure areas are required to ensure the treatment of industrially relevant operating volumes [1]. A second advantage in the operation of largescale reactors with the new prototype compared with the CPC is that the ratio of the physical area occupied by the collector to the total volume of treatment $\left(\alpha_{g}\right)$ could be lower, which would demonstrate 
its viability in the scaling of photocatalysis processes for industrial wastewater applications on a commercial scale. This means that for smaller $\alpha_{g}$ factors, fewer solar reactors and smaller footprint would be required for a given volume of treatment, which would thereby improve the costs of initial investment, maintenance, and operating costs. Table 2 shows the $\alpha_{g}$ ratios for the pilot-scale CPC reactors reported in the literature.

From the point of view of irradiated volume, four OMTPs are equivalent to seven CPCs but with higher photon efficiencies than that of the latter, as discussed below. The hydraulic optimization of the system shows that the energy consumption per liter of treated wastewater would be lower in the designed OMTP and that to maintain the turbulent flow with a flow rate higher than $24 \mathrm{~g} / \mathrm{L}$, a 0.30 -HP magnetic pump is theoretically required as opposed to a 0.24 -HP pump for a CPC. The difference in the energy cost is compensated in treating higher volumes with efficiency increases.

Table 2. Ratio of the physical area of the collector per treatment volume for solar CPC reactors and OMPT.

\begin{tabular}{llll}
\hline Reference & $\boldsymbol{A}_{T, \text { Collector }}\left(\mathrm{m}^{2}\right)$ & $\boldsymbol{V}_{T}\left(\mathrm{~m}^{3}\right)$ & $\alpha_{g}\left(\mathrm{~m}^{2} / \mathrm{m}^{3}\right)$ \\
\hline OMTP & 1.74 & 0.058 & 29 \\
CPC & 1.74 & 0.032 & 53 \\
{$[29]$} & 4.5 & 0.060 & 80 \\
{$[30]$} & 1.37 & 0.025 & 60 \\
{$[31]$} & 2.12 & 0.050 & 40 \\
{$[32]$} & 3.08 & 0.035 & 90 \\
\hline
\end{tabular}

Moreover, the initial investment costs for the construction of an OMTP module, although slightly higher than that of the CPC, are compensated for by its implementation with smaller numbers of arrays of CPC modules in series with the same arrangement and distribution. If the arrangements of the same type are considered, the cost of the construction area will be 1.8 times lower than that of the CPC. Table 3 presents the costs in US dollars at the current exchange rate for the construction of a reactor module.

Table 3. USD costs for construction of a CPC reactor and an OMTP in Colombia (Reference year 2014).

\begin{tabular}{lll}
\hline Concept & CPC & OMTP \\
\hline Borosilicate tubes & 130 & 235 \\
Collector and supports & 550 & 550 \\
\hline
\end{tabular}




\begin{tabular}{lll}
\hline Reflectors (involutes) & 100 & --- \\
Recycling tanks & 15 & 15 \\
Magnetic pump & 100 & 100 \\
PVC tubing and accessories & 85 & 120 \\
Seals, resins, adhesives, and Teflon & 80 & 90 \\
Labor & 200 & 250 \\
\hline Total & 1260 & 1360 \\
\hline Operation/day* & 13 & 14 \\
\hline$*$ Energy, catalyst and maintenance & based on 12 hours of operation, power of pump and volume of \\
treatment. &
\end{tabular}

\subsection{Evaluation of heterogeneous photocatalytic degradation of organic compounds}

\subsubsection{Degradation of methylene blue}

The performance of the heterogeneous photocatalytic degradation of methylene blue with suspended $\mathrm{TiO}_{2}-\mathrm{P} 25$ using natural solar radiation in the OMTP is shown in Figure 6. This is reported as the percentage of degradation \% Deg as a function of the accumulated UV-B energy:

$\% \operatorname{Deg}=\left(\frac{C_{M B}(\xi=0)-C_{M B}\left(\xi\left(t_{W S}\right)\right)}{C_{M B}(\xi=0)}\right) \times 100$

The reaction rates of methylene blue were the highest for accumulated energies of less than 2000 units, under optimal catalyst loading $(0.25 \mathrm{~g} / \mathrm{L})$. The rate increased at lower catalyst loadings and then decreased at higher catalyst loadings $(>0.25 \mathrm{~g} / \mathrm{L})$ as a result of the increase of the photon shielding effects. The photon scattering and shielding effects are a function of the optical thickness of the suspension, which in turn depend on the catalyst concentration, the optical properties of the catalyst suspension (absorption and scattering coefficients and scattering phase function) and the geometrical thickness of the suspension. The optical thickness at the higher catalyst concentration $(0.35 \mathrm{~g} / \mathrm{L})$ was 2.06 , while at the lower catalyst concentrations $(0.2 \mathrm{~g} / \mathrm{L})$ it was 1.18 . These results are consistent with previous simulation results reported in the literature [7]. 
However, for all four concentrations of $\mathrm{TiO}_{2}-\mathrm{P} 25$ used, degradation greater than $99 \%$ were reached for an accumulated energy of $8000 \mathrm{~J} / \mathrm{m}^{2}$ and for treatment times of less than 70 minutes. This is primarily due to the direct effects of increased residence time, illuminated reactor volume and overall absorbed solar energy, and the contribution of direct photolysis.

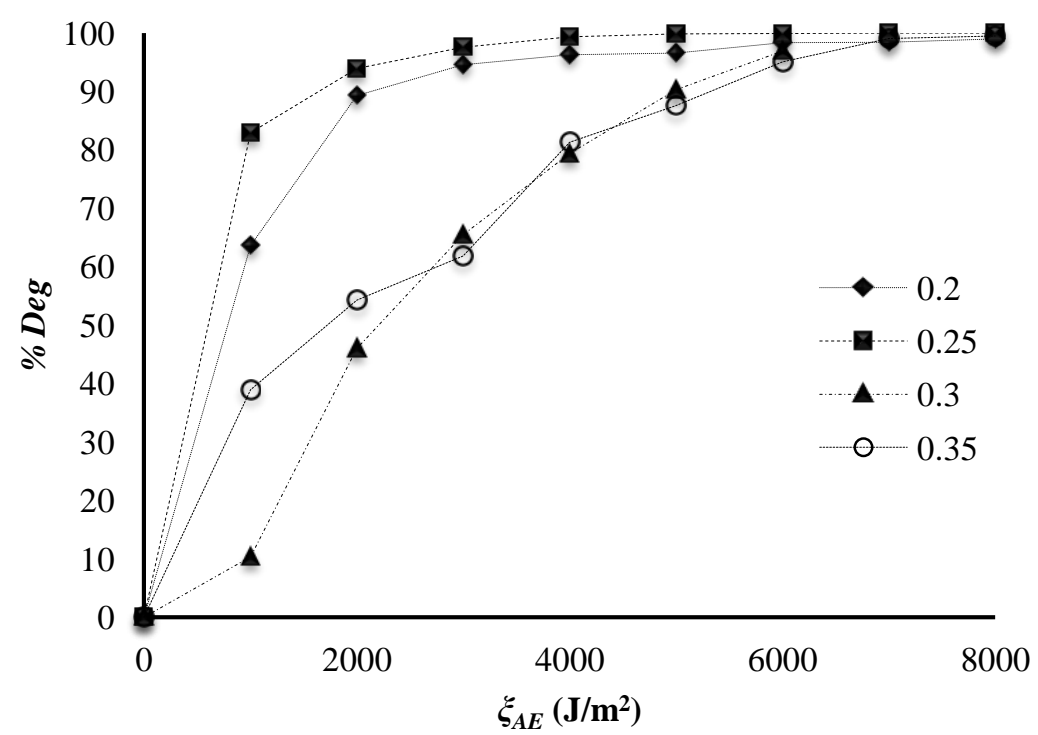

Figure 6. Performance of methylene blue degradation in a pilot-scale OMTP solar reactor at different $\mathrm{TiO}_{2}-\mathrm{P} 25$ catalyst concentrations $(0.2,0.25,0.3$, and $0.35 \mathrm{~g} / \mathrm{L})$.

The effect of direct photolysis of MB in the OMTP showed a degradation of $46 \%$ at an accumulated energy of $8000 \mathrm{~J} / \mathrm{m}^{2}$, which compares to only $10 \%$ in the CPC reactor operated under identical conditions (see Figure 7.a). This improvement in performance evidences the effect of favourable reactor geometry in the OMPT and the corresponding increase of the surface area and reactor volume exposed to the sun with respect to the CPC. Literature studies have reported degradation of methylene blue in the absence of a catalyst, obtaining values of less than $10 \%$ for CPC reactors and up to $20 \%$ in a small-scale rotary reactor using UV lamps [33-36]. Considering that this compound is highly recalcitrant and exhibits resistance to biodegradation, the effect of photolysis on the heterogeneous solar photocatalysis process may be beneficial and may decrease the contact time in large-scale treatment systems. In contrast, adsorption experiments under darkness in the pilot plant showed reductions in the initial loading of the contaminant of less than $2 \%$ during the homogenization time, therefore, these can be neglected on the effect of heterogeneous solar photocatalysis of MB.

\subsubsection{Degradation of phenol, DCA, and 4-CP}


Heterogeneous photocatalytic degradation of phenol, DCA, and 4-CP was performed in a heterogeneous photocatalytic solar platform at the University of Cartagena, Colombia $\left(10^{\circ} 25^{\prime} 25^{\prime \prime} \mathrm{N}-75^{\circ} 31^{\prime} 31^{\prime \prime} \mathrm{O}\right)$ on sunny and clear days at a specific hour to ensure that environmental atmospheric conditions did not significantly affect the process. The incident solar radiation measured during the experiment period (2016) and the slopes of the linear relationship with the accumulated UV-B radiation during the treatment time is presented in Supplementary Information (Figs. S1-S5). The observed conversion of TOC at 8000 $\mathrm{J} / \mathrm{m}^{2}$ of energy accumulated for these three compounds at different initial TOC concentrations in both the OMTP and CPC are presented in Table 4 by applying Eq. (11).

Table 4 Percentages of heterogeneous photocatalytic degradation for Phenol, DCA, and 4-CP in OMTP and CPC solar reactors for total accumulated energies of $8000 \mathrm{~J} / \mathrm{m}^{2}$.

\begin{tabular}{|c|c|c|c|c|c|c|}
\hline \multirow{3}{*}{$\begin{array}{l}\text { \%Deg } \\
\text { Reactor }\end{array}$} & \multicolumn{2}{|c|}{ Phenol } & \multicolumn{2}{|c|}{ DCA } & \multicolumn{2}{|c|}{ 4-CP } \\
\hline & $C_{T O C, 0}$ & $C_{T O C, 0}$ & $C_{T O C, 0}$ & $C_{T O C, 0}$ & $C_{T O C, 0}$ & $C_{T O C, 0}$ \\
\hline & 60 ppm & 120 ppm & 60 ppm & 120 ppm & 60 ppm & 120 ppm \\
\hline OMTP & 24.15 & 29.69 & 55.58 & 72.86 & 20.68 & 22.19 \\
\hline СРC & 20.31 & 19.36 & 53.41 & 68.26 & 28.17 & 21.42 \\
\hline$C_{\text {Cat }}$ & \multicolumn{2}{|c|}{$0.10 \mathrm{~g} / \mathrm{L}$} & \multicolumn{2}{|c|}{$0.35 \mathrm{~g} / \mathrm{L}$} & \multicolumn{2}{|c|}{$0.50 \mathrm{~g} / \mathrm{L}$} \\
\hline
\end{tabular}

The results show that for the established operating conditions, the percentages of TOC degradation favor the OMTP with respect to the CPC. The advantage of the OMTP over the CPC lies in the higher operating volume per footprint exposed to sunlight. The lower degree of phenol and 4-CP degradation in comparison to DCA, does not depend on the geometry of the reactor, but results from the highly recalcitrant intermediates that are generated during the mineralization process $[12,37,38]$. 4-CP primarily produces 4-chlorocatechol (4-CC), hydroquinone (HQ), 1,4-benzoquinone (BQ), acetylene, and maleic acid, during the treatment, however, these are consumed with the reagent by effect of the high attack of hydroxyl radicals due to high photonic performance of the reactor [23, 31, 38]. Phenol, instead generates p-benzoquinone (p-BQ), HQ, and catechol (CC), which, similarly to the 4-CP intermediates, suffer high molecular adsorption on the surface of $\mathrm{TiO}_{2}$ that competes with the multilayer adsorption of $\mathrm{H}_{2} \mathrm{O}$, thus reducing the probability of photogenerated electron capture, decreasing $\mathrm{OH}^{*}$ production, and increasing surface recombination $[39,40]$.

In contrast, the photocatalytic degradation of DCA proceeded at much higher rates compared to phenol and 4-CP, which results from the simultaneous attack by photogenerated holes $(\mathrm{h}+)$ and hydroxyl radicals 
on the dissociated dichloroacetate ions in aqueous phase [12,41]. The direct attack of dichloroacetate ions by the photogenerated holes form dichloroacetate radicals and then $\mathrm{CO}_{2}$ and dichloromethyl radicals by decarboxylation. These react with molecular oxygen adsorbed on the surface of the catalyst, forming dichloromethylperoxyl radicals. These two molecules together form $\mathrm{H}_{2} \mathrm{O}_{2}$ and phosgene. $\mathrm{H}_{2} \mathrm{O}_{2}$ enhances electron capture on the photocatalyst surface, which thereby benefits the formation of hydroxyl radicals, while phosgene is hydrolyzed to $\mathrm{HCl}$ and $\mathrm{CO}_{2}$ [41]. Simultaneously to the above mechanism, the hydroxyl radicals formed by the oxidation of water/protons at the surface of the photocatalyst may also attack DCA and the reaction intermediates $[12,17]$.

\subsubsection{Effect of geometry}

Although contaminants reaction mechanisms are intrinsic to the nature of the reagent and its interaction with the photocatalyst, the rate of generation of the oxidant species is a function of the rate of photon absorption in the reactor, which in turn depends on the reactor geometry. The degradation efficiency of $\mathrm{MB}$, phenol, DCA, and 4-CP, respectively, per unit area and per unit treatment volume, $\eta_{\alpha}$, as a function of the accumulated energy $\xi_{A E}$ in both OMTP and CPC is shown in Fig. 7. The OMTP displayed much higher efficiencies than in the CPC. After $8000 \mathrm{~J} / \mathrm{m}^{2}$ of accumulated solar energy, the $\eta_{\alpha}$ for MB degradation was $81 \%$ higher in the OMTP (Figure 7a). At higher initial concentrations (120 ppm) the $\eta_{\alpha}$ degradation for phenol was $242 \%$ higher (Figure $7 b$ ), 125\% higher for DCA (Figure 7c), and 118\% higher for 4-CP (Figure 7d) in the OMTP in comparison to the degradation efficiency in the CPC. At lower contaminant concentration (60 ppm), the $\eta_{\alpha}$ percentages were $151 \%$ (phenol), 150\% (DCA), and 55\% (4$\mathrm{CP}$ ) higher in the OMTP than in the CPC. In general, the results shown that at high initial concentration of contaminants the degradation performance always is much better in compare of low initial concentration, this is due to the reaction order which is higher than zero on evaluated systems and therefore a faster rate is expected at higher initial concentrations.

These results represent a fundamental contribution to the scaling processes of solar heterogeneous photocatalysis applications because higher efficiencies in the OMTP were obtained using the same physical installation area of collector $\left(1.74 \mathrm{~m}^{2}\right)$. In addition, the OMTP worked with a volume 1.8 times greater than the CPC volume. For multiple solar reactor panels these advantages will scale linearly. 


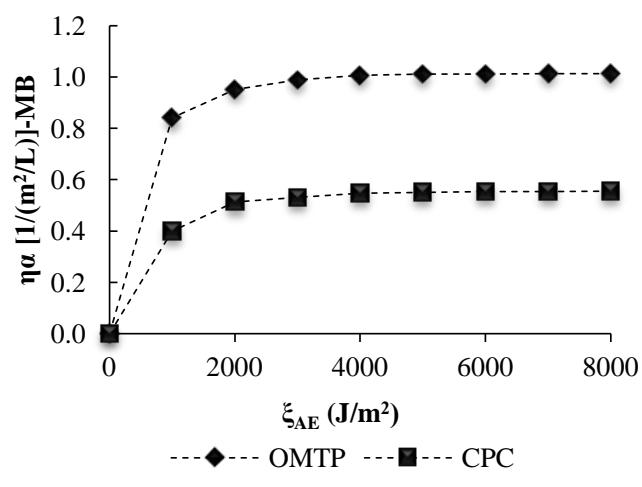

C

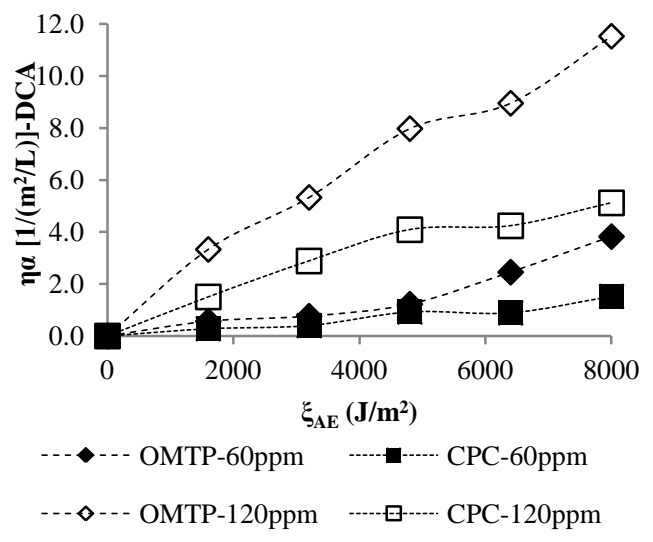

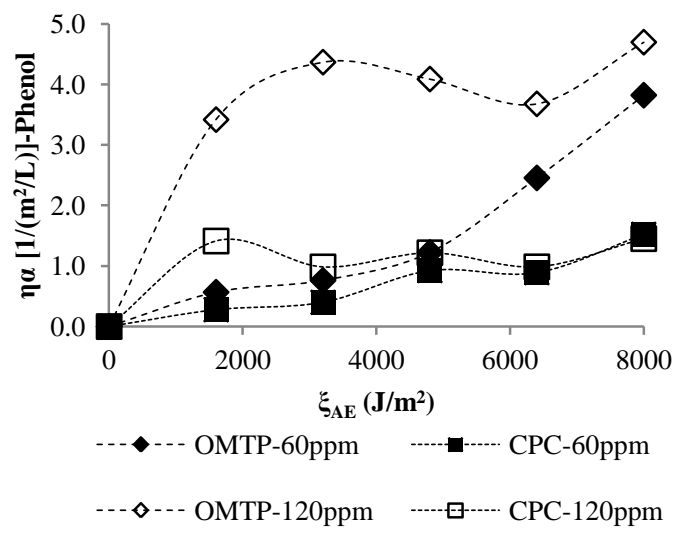

$\mathrm{b}$

d

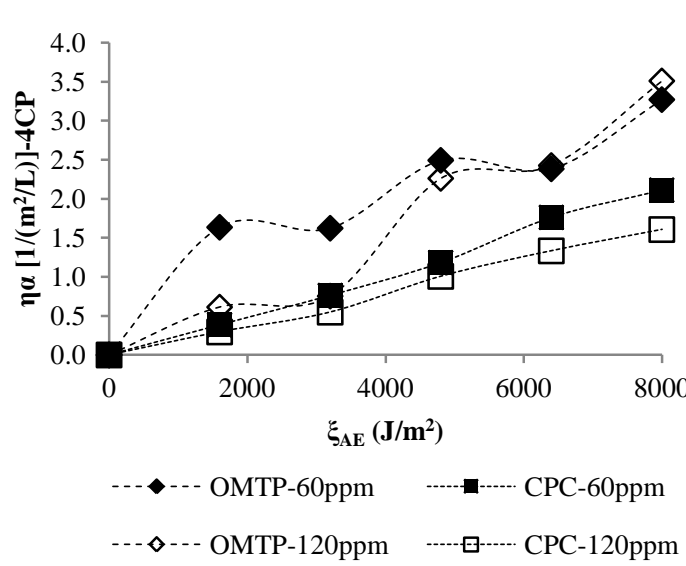

Figure 7. Efficiency of photocatalytic degradation at OMTP and CPC solar reactors per unit area and volume of operation: a) Methylene Blue b) Phenol, c) DCA and, d) 4-Chlorophenol.

\subsection{Mathematical evaluation of OMTP and CPC photoreactor performance}

Mathematical modeling of the photoreactor systems by combining the mass balances, the solution of the radiation balance (LVRPA), the reactor hydrodynamics and the reaction kinetics, permits to evaluate the concentrations of contaminants as a function of the accumulated energy. The model is also required for the design of solar water detoxification plants. The performance of the heterogeneous photocatalytic degradation processes in both OMTP and CPC was quantified by the solution of the photoreactor model (Eq. 7 coupled with Eq. 9) using the 4th-order Runge-Kutta method and the optimization algorithm of Nelder and Mead [42] for the determination of the kinetic parameters, which fits the model to the experimental results. The robustness of the mathematical model generated high predictions of the experimental data with average total error of less than $1.6 \%$ and with deviations close to zero (Figure 8). 

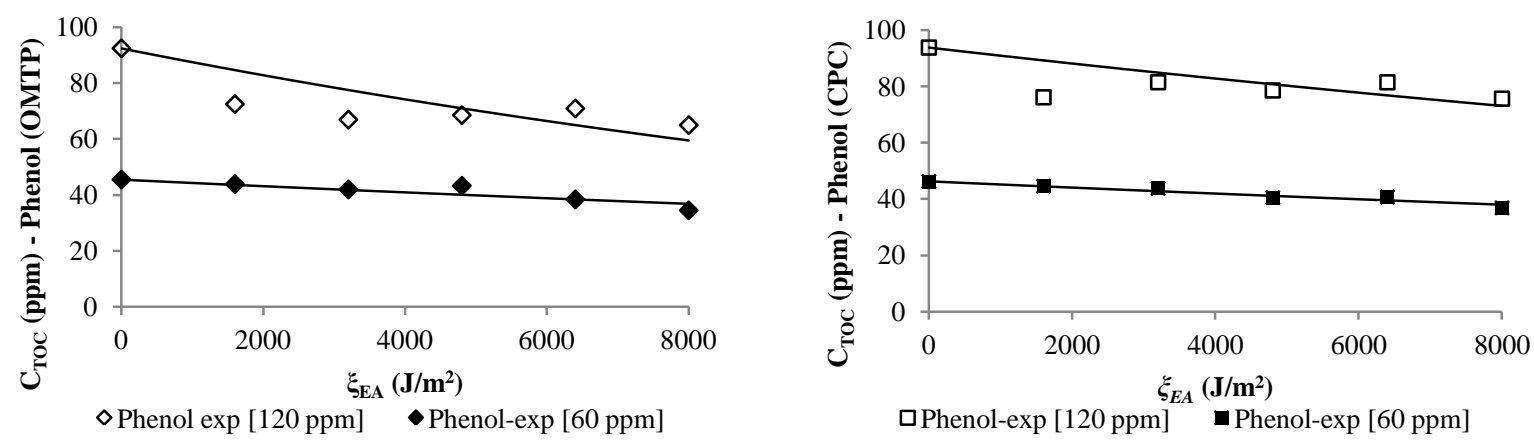

a
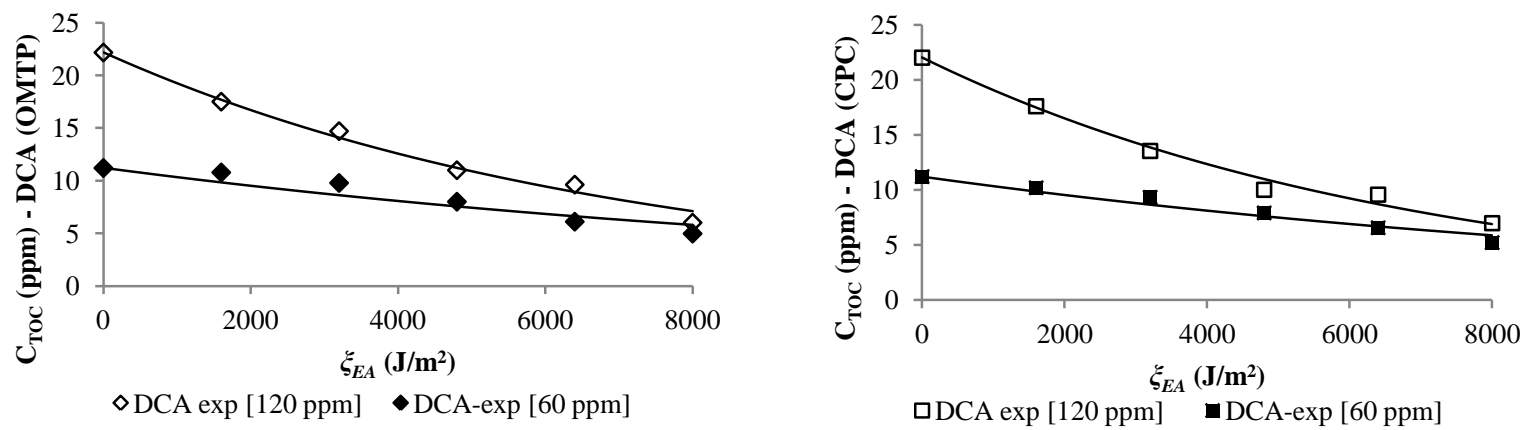

b
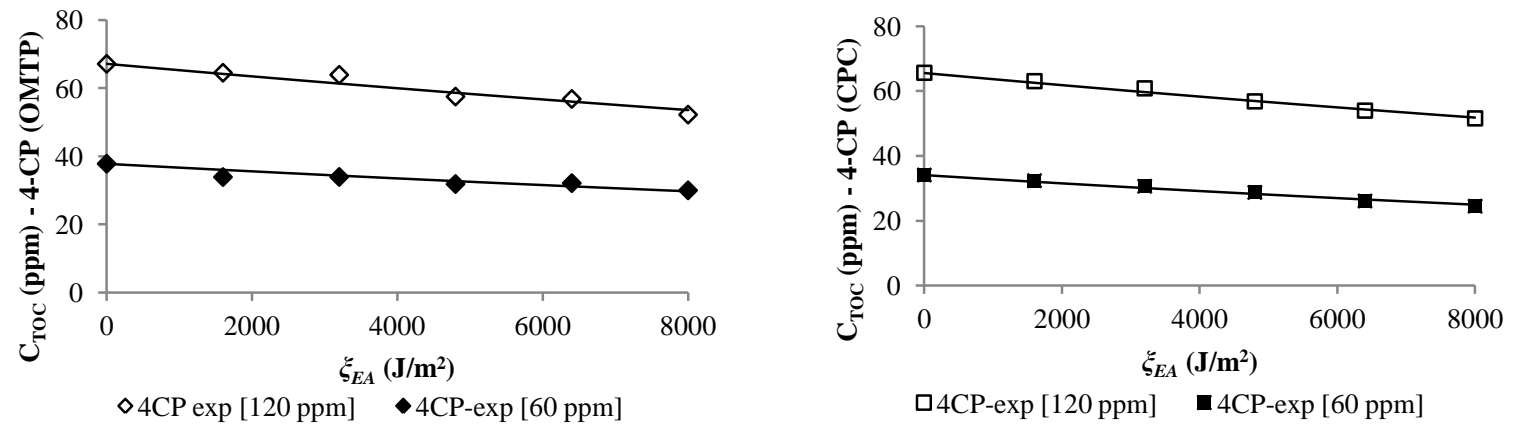

$\mathrm{c}$

Figure 8. Predictive capacity of the model for the description of heterogeneous solar photocatalytic degradation in the OMTP and CPC reactor for a) phenol, b) DCA, and c) 4-CP with suspended $\mathrm{TiO}_{2}-\mathrm{P} 25$ and natural solar radiation in Cartagena, Colombia

The determined kinetic parameters $\alpha_{1}, \kappa_{A}^{\text {L-Hand }}$ and $\eta$ are shown in Table 5. For the three compounds evaluated, the overall reaction rate efficiencies in the OMTP were 40\% (average) higher than in the CPC due to the higher rate of photon absorption and larger reactor volume. The longer mean residence time in 
the illuminated zone of the OMTP as a result of a greater number of tubes results in higher rates of contaminants mineralization incorporating the intermediates formed during the reactions (Figure 8) [1].

Table 5. Overall kinetic parameters of the model and $\eta^{*}$ parameter for photocatalytic degradation of phenol, DCA, and 4-CP.

\begin{tabular}{|c|c|c|c|c|c|c|c|}
\hline \multirow{3}{*}{ Compound } & \multirow{3}{*}{$\alpha_{1} \times 10^{4}$} & \multicolumn{2}{|l|}{ OMTP } & \multicolumn{3}{|c|}{ CPC } & \multirow{3}{*}{$\frac{\eta_{\text {OMTP }}-\eta_{C P C}}{\eta_{C P C}}$} \\
\hline & & $\kappa_{A}{ }^{L-H} \times 10^{4}$ & $\eta \times 10^{4}$ & $\alpha_{I} \times 10^{4}$ & $\kappa_{A}{ }^{L-H} \times 10^{4}$ & $\eta \times 10^{4}$ & \\
\hline & & & & & & & \\
\hline Phenol & 8.18 & 1.41 & 2.934 & 5.75 & 0.96 & 1.960 & 0.4969 \\
\hline DCA & 9.47 & 1.63 & 2.847 & 9.05 & 1.56 & 1.804 & 0.5782 \\
\hline 4-CP & 3.87 & 0.63 & 1.810 & 3.57 & 0.56 & 1.730 & 0.462 \\
\hline
\end{tabular}

$*_{\eta}$ is the degradation per unit of collector area and per treatment volume.

The kinetic performance is affected for the molecular absorption mechanisms. The generalized kinetic model used in this evaluation (Eq. 7) was based on Turchi and Ollis mechanism [8, 16, 17]. The absorptive processes in the solid-liquid interface are strongly competitive on molecular transportation of the reactive species and the kinetic of reaction rate [16]. The competition of molecular absorption of contaminant over $\mathrm{TiO}_{2}$ surface in the OMTP is also affected by the reactor geometry. The constants $\kappa_{A}{ }^{L-H}$ of the model also have higher values in the OMTP. This result is consistent due that the molecular absorption of the process is not an equilibrium process because it is a kinetic constant of adsorption. The dynamic of the competitive molecular absorption is affected by the longer residence time and the total volume of operation, whereby the effects of molecular transport of the substrates to the catalyst surface and their adsorption increase. Finally, these kinetic contributions favor photonic efficiencies $\eta(\mathrm{ppm} / \mathrm{J})$ [2], which are higher in the OMTP in comparison to the CPC reactor (Table 5), because of the higher reaction volume and total solar power absorbed in this reactor.

\section{CONCLUSIONS}

This study has presented a new solar reactor prototype (OMTP) which addresses some of the limitations of current CPC solar reactors used in industrial wastewater treatment. The OMTP increase the total treatment volume, the residence time, decrease the footprint, and simplify scale-up in comparison to the CPC. This new reactor includes an additional arrangement of tubes in the space occupied by the CPC involutes. The fluid residence time in the OMPT increased by up to 1.8 times. The net solar global energy absorbed in the OMPT increased by up to $44 \%$, which translated in MB, DCA, 4-CP and phenol 
degradation efficiencies up to $81 \%, 125 \%, 118 \%$ and $242 \%$ higher, respectively, in comparison to the CPC after $8000 \mathrm{~J} / \mathrm{m}^{2}$ of accumulated solar energy. Optimization of the reaction volume/volume ratio was achieved by obtaining a minimum $\beta$ factor of 0.27 , which guaranteed turbulent conditions with $\operatorname{Re}>$ 20,000, perfect mixing of particles, and avoided the sedimentation of the catalyst. In addition, this condition is the requirement for the hydrodynamic operation of the pumping system. The overall net energy, i.e., OVRPA, associated with the operation of the two reactors was calculated, and a greater availability of radiant energy was found in the reaction phase space for the OMTP, $412.3 \mathrm{~W} / \mathrm{m}^{3}$ for the CPC (10 tubes) and $653.04 \mathrm{~W} / \mathrm{m}^{3}$ for the OMTP (18 tubes), which is consistent with the experimental results of the degradation of organic pollutants studied. The efficiencies per unit area and volumetric unit of treatment demonstrated the absolute superiority of the OMTP for larger overall volumes, which indicated that the reactor is potentially better for scaling and requires a smaller number of collectors for large volumes of wastewater. Finally, the costs of OMTP was competitive and comparable with conventional CPC solar photoreactor. Further improvements on the performance of the OMTP for water treatment and purification, should include the use of efficient solar responsive photocatalysts.

\section{Acknowledgements}

The authors thank the Universidad de Cartagena (Colombia), Universidad del Valle (Colombia), and Loughborough University (United Kingdom) for funding this publication. Mueses thanks the British Council for the Newton Fund Grant: Researcher Links-BC 030-EDU2016 for funding the stay in the United Kingdom for the development of this publication, COLCIENCIAS (Colombia) for funding doctoral studies, and the Office of the Vice-Head for Research of the University of Cartagena through the

Group Strengthening Project 060-2015 for funding this research.

\section{REFERENCES}

[1] S. Malato, M. I. Maldonado, P. Fernández-Ibáñez, I. Oller, I. Polo, R. Sánchez-Moreno, Decontamination and disinfection of water by solar photocatalysis: The pilot plants of the Plataforma Solar de Almeria, Mat. Sci. Semicon. Proc. 42 (2016) 15-23.

[2] D. Spasiano, R. Marotta, S. Malato, P. Fernandez-Ibañez, I. Di Somma, Solar photocatalysis: Materials, reactors, some commercial, and pre-industrialized applications. A comprehensive approach, Appl. Catal. B: Env. 170-171 (2015) 90-123.

[3] S. Malato, J. Blanco, A. Vidal, D. Alarcón, M. I. Maldonado, J. Cáceres, W. Gernjak, Applied studies in solar photocatalytic detoxification: an overview, Sol. Energy. 75 (2003) 329-336. 
[4] M. N. Chong, B. Jin, C. W. K. Chow, C. Saint, Recent developments in photocatalytic water treatment technology: a review, Wat. Res. 44 (2010) 2997-3027.

[5] N. De la Cruz, R. F. Dantas, J. Giménez, S. Esplugas, Photolysis and $\mathrm{TiO}_{2}$ photocatalysis of the pharmaceutical propranolol: Solar and artificial light, Appl. Catal. B: Env. 130-131 (2013) 249-256.

[6] R. J. Braham, A. T. Harris, Review of Major Design and Scale-up Considerations for Solar Photocatalytic Reactors, Ind. Eng. Chem. Res. 48 (2009) 8890-8905.

[7] J. Colina-Márquez, F. Machuca-Martínez, G. Li Puma, Radiation absorption and optimization of solar photocatalytic reactors for environmental applications, Environ. Sci. Technol. 44 (2010) 5112-5120.

[8] A. E. Cassano, O. M. Alfano, Reaction engineering of suspended solid heterogeneous photocatalytic reactors, Catal. Today. 58 (2000) 167-197.

[9] O. M. Alfano, A. E. Cassano, Advances in Chemical Engineering-Photocatalytic Technologies, Adv. Chem. Eng. 36 (2009) 229-287.

[10] O. Alfano, D. Bahnemann, A. Cassano, R. Dillert, R. Goslich, Photocatalysis in water environments using artificial and solar light, Catal. Today. 58 (2000) 199-230.

[11] V. Romero, O. González, B. Bayarri, P. Marco, J. Giménez, S. Esplugas, Degradation of Metoprolol by photo-Fenton: Comparison of different photoreactors performance, Chem. Eng. J. 283 (2016) 639-648.

[12] R. Dillert, A. E. Cassano, R. Goslich, D. Bahnemann, Large scale studies in solar catalytic wastewater treatment, Catal. Today, 54 (1999) 267-282.

[13] O. A. McLoughlin, P. Fernández Ibáñez, W. Gernjak, S. Malato Rodriguez, L. W. Gill, Photocatalytic disinfection of water using low cost compound parabolic collectors, Sol. Energy. 77 (2004) 625-633.

[14] O. A. McLoughlin, S. C. Kehoe, K. G. McGuigan, E. F. Duffy, F. Al Touati, W. Gernjak, I. Oller Alberola, S. Malato Rodriguez, L.W. Gill, Solar disinfection of contaminated water: a comparison of three small-scale reactors, Sol. Energy. 77 (2004) 657-664.

[15] J. Colina-Márquez, F. Machuca-Martínez, G. Li Puma, Photocatalytic mineralization of commercial herbicides in a pilot-scale solar CPC reactor: Photoreactor modeling and reaction kinetics constants independent of radiation field, Environ. Sci. Technol. 43 (2009) 8953-8960.

[16] M. A. Mueses, F. Machuca-Martinez, G. Li Puma, Effective quantum yield and reaction rate model for evaluation of photocatalytic degradation of water contaminants in heterogeneous pilot-scale solar photoreactors, Chem. Eng. J. 215-216 (2013) 937-947.

[17] G. Sagawe, M. L. Satuf, R. J. Brandi, J. P. Muschner, C. Federer, O. M. Alfano, D. Bahnemann, A. E. Cassano, Analysis of photocatalytic reactors employing the photonic efficiency and the removal efficiency parameters: Degradation of radiation absorbing and nonabsorbing pollutants, Ind. Eng. Chem. Res. 49 (2010) 6898-6908. 
[18] G. Li Puma, Dimensionless Analysis of Photocatalytic Reactors Using Suspended Solid Photocatalyst, Chem. Eng. Res. Des. 83 (2005) 820-826.

[19] A. L. L. Zazueta, H. Destaillats, G. Li Puma, Radiation field modeling and optimization of a compact and modular multi-plate photocatalytic reactor (MPPR) for air/water purification by Monte Carlo method, Chem. Eng. J. 217 (2013) 475-485.

[20] J. Marugán, R. van Grieken, A. E. Cassano, O. M. Alfano, Scaling-up of slurry reactors for the photocatalytic oxidation of cyanide with $\mathrm{TiO} 2$ and silica-supported $\mathrm{TiO} 2$ suspensions, Cat. Today. 144 (2009) 87-93.

[21] J. Marugán, R. van Grieken, C. Pablos, M. L. Satuf, A. E. Cassano, O. M. Alfano, Modeling of a bench-scale photocatalytic reactor for water disinfection from laboratory-scale kinetic data, Chem. Eng. J. 224 (2013) 39-45.

[22] C. S. Zalazar, M. D. Labas, C. A. Martín, R. J. Brandi, A. E. Cassano, Reactor scale-up in AOPs: From laboratory to commercial scale, Water. Sci Technol. 49 (2004) 13-18.

[23] M. L. Satuf, R. J. Brandi, A. E. Cassano, O. M. Alfano, Scaling-up of slurry reactors for the photocatalytic degradation of 4-chlorophenol, Catal. Today. 129 (2007) 110-117.

[24] R. Acosta-Herazo, J. Monterroza-Romero, M. Á. Mueses, F. Machuca-Martínez, G. Li Puma, Coupling the Six Flux Absorption-Scattering Model to the Henyey-Greenstein scattering phase function: Evaluation and optimization of radiation absorption in solar heterogeneous photoreactors, Chem. Eng. J. 302 (2016) 86-96.

[25] G. C. Roda, F. Santarelli, A rational approach to the design of photocatalytic reactors, Ind. Eng. Chem. Res. 46 (2007) 7637-7644.

[26] F. Machuca-Martínez, M. Á. Mueses, J. Colina-Márquez, G. Li Puma, Photocatalytic reactor modeling, in: J. Schneider, D. Bahnemann, J. Ye, G. Li Puma, D. D. Dionysiou (Eds.), Photocatalysis: fundamentals and perspectives, Royal Society of Chemistry, London 2016, pp. 388424.

[27] N. Suaterna-Ortíz, C. Insignares-Rendón, M. Mueses, R. Camargo, Pilot scale heterogeneous solar photodegradation of 4-chlorophenol in a cylindrical parabolic composed reactor (CPC), Informacion Tecnologica. 23 (2012) 13-24.

[28] M. L. Satuf, R. J. Brandi, A. E. Cassano, O. M. Alfano, Experimental Method to Evaluate the Optical Properties of Aqueous Titanium Dioxide Suspensions, Ind. Eng. Chem. Res. 44 (2005) 6643-6649.

[29] M. I. Polo-López, M. Castro-Alférez, I. Oller, P. Fernández-Ibáñez, Assessment of solar photoFenton, photocatalysis, and $\mathrm{H}_{2} \mathrm{O}_{2}$ for removal of phytopathogen fungi spores in synthetic and real effluents of urban wastewater, Chem. Eng. J. 257 (2014) 122-130.

[30] K. Villa, X. Domènech, S. Malato, M. I. Maldonado, J. Peral, Heterogeneous photocatalytic hydrogen generation in a solar pilot plant, Int. J. Hydrogen Energ. 38 (2013) 12718-12724. 
[31] F. Sciacca, J. A. Rengifo-Herrera, J. Wéthé, C. Pulgarin, Solar disinfection of wild Salmonella sp. in natural water with a $18 \mathrm{~L} \mathrm{CPC}$ photoreactor: Detrimental effect of non-sterile storage of treated water, Sol. Energy. 85 (2011) 1399-1408.

[32] M. Kositzi, I. Poulios, S. Malato, J. Caceres, A. Campos, Solar photocatalytic treatment of synthetic municipal wastewater, Wat. Res. 38 (2004) 1147-54.

[33] T. Zhang, T. Oyama, A. Aoshima, H. Hidaka, J. Zhao, N. Serpone, Photooxidative N-demethylation of methylene blue in aqueous TiO2 dispersions under UV irradiation, J. Photochem. Photobiol., A: Chem. 140 (2001) 163-172.

[34] W. S. Kuo, P. H. Ho, Solar photocatalytic decolorization of methylene blue in water, Chemosphere. 45 (2001) 77-83.

[35] M. A. Rauf, M. A. Meetani, S. Hisaindee, An overview on the photocatalytic degradation of azo dyes in the presence of TiO2 doped with selective transition metals, Desalination. 276 (2001) 13-27.

[36] K. Rajeshwar, M. E. Osugi, W. Chanmanee, C. R. Chenthamarakshan, R. V. B. Zanoni, P. Kajitvichyanukul, R. Krishnan-Ayer, Heterogeneous photocatalytic treatment of organic dyes in air and aqueous media, J. Photochem. Photobiol., C: Photochem. Rev. 9 (2008) 171-192.

[37] D. Curcó, S. Malato, J. Blanco, J. Giménez, P. Marco, Photocatalytic degradation of phenol: Comparison between pilot-plant-scale and laboratory results, Sol. Energy. 56 (1996) 387-400.

[38] S. Ahmed, M. G. Rasul, W. N. Martens, R. Brown, M. A. Hashib, Heterogeneous photocatalytic degradation of phenols in wastewater: A review on current status and developments, Desalination. 261 (2010) 3-18.

[39] L. Mino, A. Zecchina, G. Martra, A. M. Rossi, G. Spoto, A surface science approach to $\mathrm{TiO}_{2} \mathrm{P} 25$ photocatalysis: An in situ FTIR study of phenol photodegradation at controlled water coverages from sub-monolayer to multilayer, Appl. Catal. B: Environ. 196 (2016) 135-141.

[40] A. Shet, S. K. Vidya, Solar light mediated photocatalytic degradation of phenol using Ag core TiO2 shell (Ag@TiO2) nanoparticles in batch and fluidized bed reactor, Sol. Energy. 127 (2016) 6778.

[41] C. S. Zalazar, R. L. Romero, C. A. Martín, A. E. Cassano, Photocatalytic intrinsic reaction kinetics I: Mineralization of dichloroacetic acid, Chem. Eng. Sci. 60 (2005) 5240-5254.

[42] H. L. Otálvaro-Marín, M. A. Mueses, F. Machuca-Martínez, Boundary layer of photon absorption applied to heterogeneous photocatalytic solar flat plate reactor design, Int. J. Photoenergy. 2014 (2014) https://doi.org/10.1155/2014/930439 

Supplementary Material
Click here to download Supplementary Material: Supporting Information-OMTP Manuscript.docx

Supplementary Material
Click here to download Supplementary Material: Supporting Information-OMTP Manuscript.docx

\begin{abstract}
Ch here to download Supplementary Material Supporting Information-OMTP Manuscript.docx
\end{abstract}

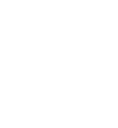

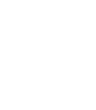

.

.

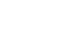

.

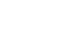

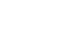

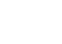

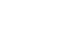

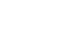

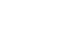

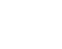

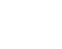

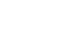

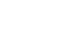

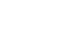

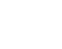

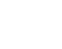

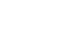

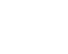

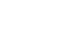

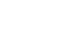

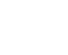

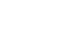

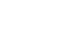

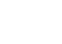

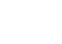

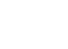

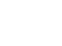

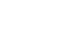

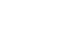

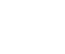

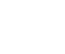

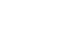

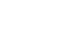

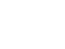

